\title{
The Mycobiome in Health and Disease: Emerging Concepts, Methodologies and Challenges
}

\author{
Pei Yee Tiew • Micheál Mac Aogain • Nur A’tikah Binte Mohamed Ali • \\ Kai Xian Thng • Karlyn Goh · Kenny J. X. Lau · Sanjay H. Chotirmall $\mathbb{C}$
}

Received: 15 July 2019/Accepted: 2 December 2019/Published online: 1 January 2020

(C) Springer Nature B.V. 2020

\begin{abstract}
Fungal disease is an increasingly recognised global clinical challenge associated with high mortality. Early diagnosis of fungal infection remains problematic due to the poor sensitivity and specificity of current diagnostic modalities. Advances in sequencing technologies hold promise in addressing these shortcomings and for improved fungal detection and identification. To translate such emerging approaches into mainstream clinical care will require refinement of current sequencing and analytical
\end{abstract}

Handling Editor: J. P. Xu.

Pei Yee Tiew and Micheál Mac Aogáin contributed equally.

P. Y. Tiew - M. Mac Aogain · N. A. B. M. Ali ·

K. X. Thng - K. J. X. Lau - S. H. Chotirmall ( $\square)$

Lee Kong Chian School of Medicine, Nanyang

Technological University, 11 Mandalay Road,

Singapore 308232, Singapore

e-mail: schotirmall@ntu.edu.sg

\section{P. Y. Tiew}

Department of Respiratory and Critical Care Medicine,

Singapore General Hospital, Singapore, Singapore

K. Goh

School of Biological Sciences, Nanyang Technological

University, Singapore, Singapore

\section{K. J. X. Lau}

Singapore Centre for Environmental Life Sciences Engineering, Nanyang Technological University,

Singapore, Singapore platforms, ensuring standardisation and consistency through robust clinical benchmarking and its validation across a range of patient populations. In this stateof-the-art review, we discuss current diagnostic and therapeutic challenges associated with fungal disease and provide key examples where the application of sequencing technologies has potential diagnostic application in assessing the human 'mycobiome'. We assess how ready access to fungal sequencing may be exploited in broadening our insight into hostfungal interaction, providing scope for clinical diagnostics and the translation of emerging mycobiome research into clinical practice.

Keywords Mycobiome - ITS sequencing · Metagenomics · Bioinformatics · Clinical

\section{Introduction}

Fungal disease affects over 300 million people worldwide causing over 1.6 million deaths annually [1]. Despite their natural environmental abundance, few fungi are human pathogens, and while fulminant fungal infection is uncommon in the healthy individuals, invasive fungal disease is a concern in the immuno-compromised host with significant associated morbidity and mortality [2]. Increasing numbers of patients are at risk of invasive fungal disease 
including those with human immunodeficiency virus (HIV), malignancy and transplant recipients on immunosuppressive or immunomodulatory therapies, each contributing to the rising global trend of fungal infections among susceptible populations. Global warming and climate change also have significant impacts on the pathogenicity and survival of fungi [3]. Acclimatisation to higher temperatures increases their ability to replicate in the human body with high basal temperature, resulting in increased pathogenic potential even for species previously reported as nonpathogenic [3]. This impacts fungal distribution where increases in heat-resistant species facilitate human interaction, infection and transmission through skin contact, inhalation and/or ingestion [3]. Fungal infection therefore can manifest as superficial infections of the skin, nail, hair and mucous membranes, by dermatophytes and Candida spp. or as invasive disease caused by opportunistic and endemic mycoses [4]. Superficial disease is generally mild and easily diagnosed with readily available treatment. However, in the immuno-compromised individual, such infections may progress to invasive disease. Opportunistic fungal disease is primarily seen in the immunocompromised with aspergillosis, candidiasis and cryptococcosis most commonly reported. The annual incidence ranges from 200,000 to 1 million, with high and variable mortality rates ranging from 20 to $90 \%$ [5]. Table 1 and Fig. 1 summarise the most common invasive fungal diseases and the anatomical sites involved. Endemic fungal diseases occur in distinct geographic regions, apparently driven by environment and climate. Irrespective of underlying host immunity, individuals residing in endemic regions are at higher risk of life-threatening disease. Blastomycosis and histoplasmosis are endemic in the Midwestern United States (US), coccidioidomycosis in the Southwestern US, paracoccidioidomycosis in Brazil and talaromycosis in Southeast Asia [5]. Worryingly, endemic fungal disease continues to propagate even expanding beyond traditional accepted boundaries, again driven at least in part by climate change, urbanisation, land development and ease of travel [6]. A key example is the outbreak of Cryptococcus gattii at Vancouver Island and the Pacific Northwest of the USA [7]. This poses significant and emerging challenges for diagnosis, which in turn delays treatment initiation with adverse clinical consequence.

\section{Diagnostic and Treatment Challenges in Fungal Infection}

The early diagnosis and initiation of therapy for fungal infection is critical, influencing outcome and mortality, particularly in the immuno-compromised [8-10]. Current available diagnostic modalities lack sensitivity and specificity, and therefore the diagnosis of invasive fungal disease relies on a combined clinical, microbiological and radiological approach with empirical treatment often initiated based on clinical judgment alone pending diagnostic confirmation [11]. Patient characteristics including the presence or absence of neutropenia or use of antifungal prophylaxis impact the diagnostic accuracy of tests, adding additional uncertainty [12-14]. The ability to distinguish infection from colonisation poses an additional and important clinical challenge. Conventional culture methods provide species-level identification and information on antifungal susceptibility. However, culture-based methods are poorly sensitive and delay time to diagnosis [15-17]. Their accuracy is contingent on sample source, type of fungus, as well as disease and host immune status. For instance, Pneumocystis species are unable to grow on culture media [18, 19] and isolation of Aspergillus in blood is uncommon and ineffective for the diagnosis of invasive aspergillosis [16, 20]. In addition, positive cultures obtained from non-sterile body sites may not be representative and should be interpreted with caution. Direct microscopic examination is useful in providing rapid and more accurate diagnosis of fungal infection allowing differentiation by their morphology and staining [21]. However, as with culture, the diagnostic yield is contingent on several factors and exhibits variable accuracy [22]. Non-culture-based techniques are increasingly employed to aid the diagnosis of invasive fungal disease. For example, detection of $\beta$-glucan, a component of the fungal cell wall, identifies patients with invasive disease with sensitivities ranging from $50-100 \%$ and specificities of $44-98 \%$ [15, 23, 24]. The high false positive rate, however, limits the usefulness of this approach particularly in high-risk patient groups including patients with haematological malignancy, stem cell and lung transplant recipients, where co-existing bacterial infection is present and in those receiving haemodialysis [25-27]. While $\beta$-glucan is a useful diagnostic target, it is not specific to any single fungal 
Table 1 Review of major invasive fungal disease with organ involvement, disease manifestation, susceptibility, diagnosis and management

\begin{tabular}{|c|c|c|c|c|}
\hline Fungal infection & Mortality & Organisms & $\begin{array}{l}\text { Organ } \\
\text { involvement }\end{array}$ & Disease manifestations \\
\hline \multirow[t]{4}{*}{ Aspergillosis } & \multirow[t]{4}{*}{$30-95 \%[228]$} & \multirow{4}{*}{$\begin{array}{l}\text { A. fumigatus } \\
\text { A. niger } \\
\text { A. flavus } \\
\text { A. terreus }\end{array}$} & Pulmonary & Pneumonia, cavity, aspergilloma, tracheobronchitis [229] \\
\hline & & & CNS & $\begin{array}{l}\text { Meningitis, meningoencephalitis, cerebral infarction, } \\
\text { haemorrhage, mycotic aneurysm [232] }\end{array}$ \\
\hline & & & GIT & $\begin{array}{l}\text { Intestinal oedema, obstruction, haemorrhage, perforation } \\
\text { [233] }\end{array}$ \\
\hline & & & Cutaneous & $\begin{array}{l}\text { Pustules, haemorrhagic bulla, ulcerative lesion, cellulitis, } \\
\text { abscess [234] }\end{array}$ \\
\hline \multirow[t]{6}{*}{ Candidiasis } & \multirow{6}{*}{$\begin{array}{l}19-30 \% \\
{[235,236]}\end{array}$} & C. albican & Blood & Candidaemia [237] \\
\hline & & C. tropicalis & Pulmonary & Pneumonia [237] \\
\hline & & C.glabrata & CNS & Meningitis, abscess [232] \\
\hline & & C. krusei & Eye & Chorioretinitis, endophthalmitis [238] \\
\hline & & & GIT & Peritonitis, oesophagitis, liver abscess [237] \\
\hline & & parapsilosis & Mucosal & Oral, vulvovaginal candidiasis [237] \\
\hline \multirow[t]{3}{*}{ Cryptococcosis } & \multirow[t]{3}{*}{$20-70 \%[228]$} & \multirow{3}{*}{$\begin{array}{l}\text { C. } \\
\text { neoformans } \\
\text { C. gattii }\end{array}$} & Pulmonary & Cryptococcoma, pneumonia [239] \\
\hline & & & CNS & Meningitis, cerebral cryptococcoma [232] \\
\hline & & & Cutaneous & Nodules, ulcerated lesion [239] \\
\hline \multirow[t]{4}{*}{ Mucormycosis } & \multirow[t]{4}{*}{$\begin{array}{l}46-96 \% \\
{[241]}\end{array}$} & \multirow{4}{*}{$\begin{array}{l}\text { Rhizopus spp. } \\
\text { Mucor spp. } \\
\text { Rhizomисor } \\
\text { spp. } \\
\text { Lichtheimia } \\
\text { spp. }\end{array}$} & $\begin{array}{l}\text { Rhino- } \\
\text { cerebral }\end{array}$ & $\begin{array}{l}\text { Sinusitis, meningitis, orbital oedema, cellulitis, nasal } \\
\text { necrotic/ulcerative lesion [242] }\end{array}$ \\
\hline & & & Pulmonary & Pneumonia, cavity, nodules, mass [243] \\
\hline & & & Cutaneous & $\begin{array}{l}\text { Nodules, ulcer, scaly plaques, cellulitis, necrotic eschar } \\
\text { [244] }\end{array}$ \\
\hline & & & GIT & $\begin{array}{l}\text { Necrotising enterocolitis, intestinal perforation, } \\
\text { ulceration [245] }\end{array}$ \\
\hline \multirow[t]{2}{*}{ Pneumocystis } & \multirow[t]{2}{*}{$20-80 \%[228]$} & \multirow[t]{2}{*}{$P$. jirovecii } & Pulmonary & Pneumonia [9] \\
\hline & & & $\begin{array}{l}\text { Extra- } \\
\text { pulmonary }\end{array}$ & $\begin{array}{l}\text { Eye, ear, thyroid, GIT, bone marrow, muscle, lymph } \\
\text { node involvement }[247,248]\end{array}$ \\
\hline \multirow[t]{5}{*}{ Blastomycosis } & \multirow{5}{*}{$\begin{array}{l}0.06-68 \% \\
\quad[228,249]\end{array}$} & \multirow{5}{*}{$\begin{array}{l}\text { B. } \\
\quad \text { dermatitidis } \\
\text { B. gilchristii }\end{array}$} & $\mathrm{CNS}$ & Meningitis, brain and epidural abscess [250] \\
\hline & & & Cutaneous & Papulopustular, ulcerative, verrucous, crusted lesions \\
\hline & & & GUT & $\begin{array}{l}\text { Prostatitis, epididymitis, tubo-ovarian abscess, } \\
\text { endometritis, salpingitis }\end{array}$ \\
\hline & & & Pulmonary & Pneumonia \\
\hline & & & Bone & Osteomyelitis \\
\hline \multirow[t]{4}{*}{ Histoplasmosis } & \multirow[t]{4}{*}{$\begin{array}{l}5-60 \% \\
{[9,228,252]}\end{array}$} & \multirow[t]{4}{*}{$\begin{array}{l}\text { H. } \\
\quad \text { capsulatum }\end{array}$} & Pulmonary & $\begin{array}{l}\text { Pneumonia, nodule, cavity, fibrosing mediastinitis, } \\
\text { broncholithiasis }[225,253,254]\end{array}$ \\
\hline & & & Cutaneous & Erythema nodosum, erythema multiforme [227] \\
\hline & & & CNS & Meningitis, parenchymal lesion $[227,232]$ \\
\hline & & & GIT & Ulceration, stricture [227] \\
\hline \multirow[t]{4}{*}{ Coccidioidomycosis } & \multirow[t]{4}{*}{$1-70 \%[228]$} & \multirow{4}{*}{$\begin{array}{l}\text { Coccidioides } \\
\text { immitis } \\
\text { Coccidioides } \\
\text { posadasii }\end{array}$} & Pulmonary & Pneumonia, nodules, cavity [256] \\
\hline & & & Cutaneous & $\begin{array}{l}\text { Erythema nodosum, erythema multiforme, nodule, } \\
\text { plaque, papules [258] }\end{array}$ \\
\hline & & & $\begin{array}{l}\text { Bone and } \\
\text { Joint }\end{array}$ & Osteomyelitis, arthritis, abscess $[259,260]$ \\
\hline & & & CNS & Meningitis [256] \\
\hline
\end{tabular}


Table 1 continued

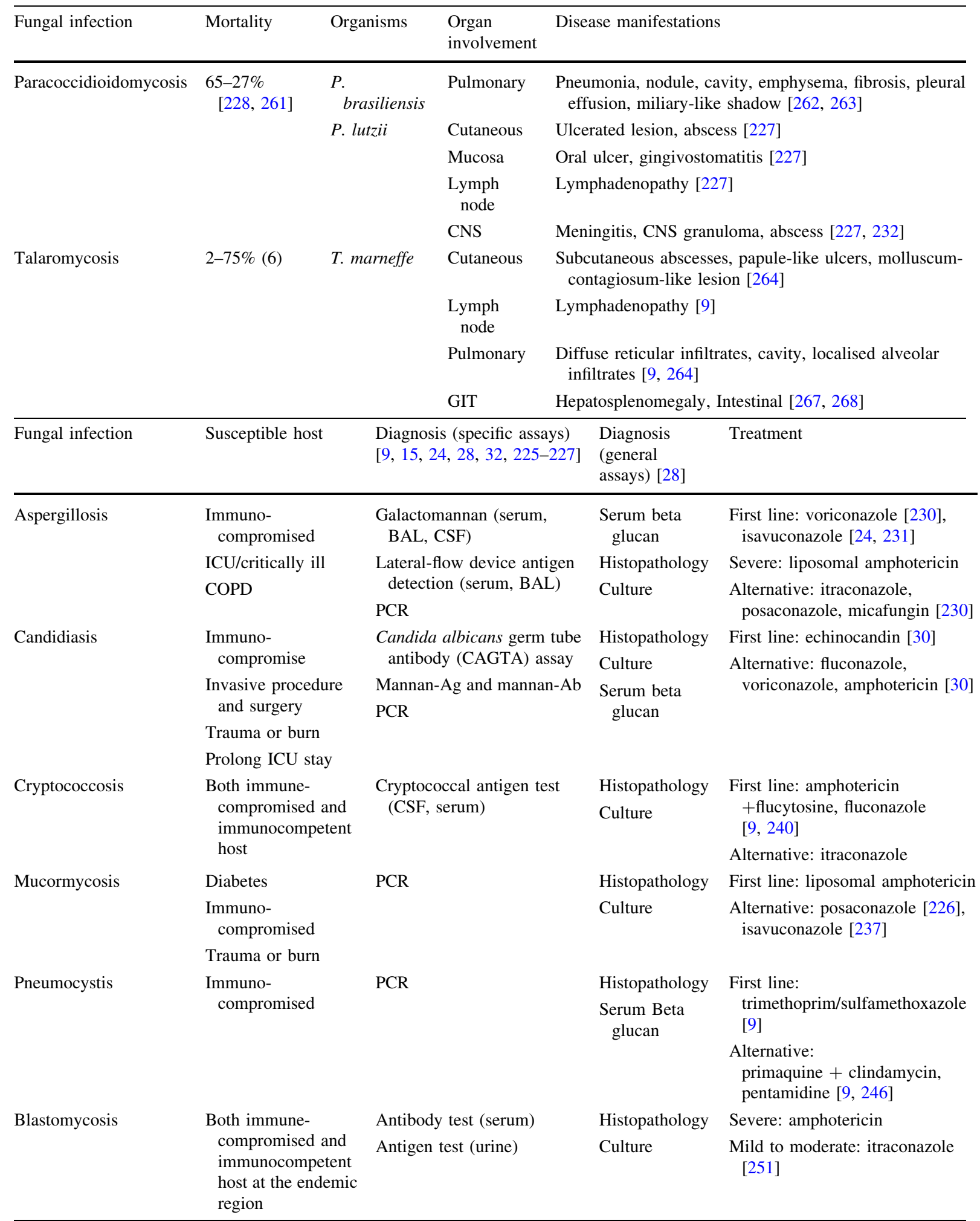


Table 1 continued

\begin{tabular}{|c|c|c|c|c|}
\hline Fungal infection & Susceptible host & $\begin{array}{l}\text { Diagnosis (specific assays) } \\
{[9,15,24,28,32,225-227]}\end{array}$ & $\begin{array}{l}\text { Diagnosis } \\
\text { (general } \\
\text { assays) [28] }\end{array}$ & Treatment \\
\hline Histoplasmosis & $\begin{array}{l}\text { Both immune- } \\
\text { compromised and } \\
\text { immunocompetent } \\
\text { host at the endemic } \\
\text { region }\end{array}$ & $\begin{array}{l}\text { Antibody test (serum) } \\
\text { Antigen test (urine, serum) }\end{array}$ & $\begin{array}{l}\text { Histopathology } \\
\text { Culture }\end{array}$ & $\begin{array}{l}\text { Severe: liposomal amphotericin } \\
\text { [225] } \\
\text { Mild to moderate: itraconazole } \\
\text { [255] } \\
\text { Mild disease treatment is usually } \\
\text { not require [255] }\end{array}$ \\
\hline Coccidioidomycosis & $\begin{array}{l}\text { Both immune- } \\
\text { compromised and } \\
\text { immunocompetent } \\
\text { host at the endemic } \\
\text { region }\end{array}$ & Antibody test (serum) & $\begin{array}{l}\text { Histopathology } \\
\text { Culture }\end{array}$ & $\begin{array}{l}\text { First line: fluconazole/itraconazole } \\
\text { [257] } \\
\text { Severe: amphotericin [257] }\end{array}$ \\
\hline Paracoccidioidomycosis & $\begin{array}{l}\text { Both immune- } \\
\text { compromised and } \\
\text { immunocompetent } \\
\text { host at the endemic } \\
\text { region }\end{array}$ & Antibody test (serum) & $\begin{array}{l}\text { Histopathology } \\
\text { Culture }\end{array}$ & $\begin{array}{l}\text { First line: itraconazole }[225,227] \\
\text { Severe: amphotericin }[225,227] \\
\text { Alternative: } \\
\text { trimethoprim/sulfamethoxazole, } \\
\text { voriconazole, posaconazole, } \\
\text { isavuconazole [227] }\end{array}$ \\
\hline Talaromycosis & $\begin{array}{l}\text { Immuno- } \\
\text { compromised }\end{array}$ & $\begin{array}{l}\text { PCR } \\
\text { Serology (not widely } \\
\text { available) }\end{array}$ & $\begin{array}{l}\text { Histopathology } \\
\text { Culture } \\
\text { Galactomannan }\end{array}$ & $\begin{array}{l}\text { First line: liposomal amphotericin } \\
\text { and itraconazole }[9,265] \\
\text { Alternative: voriconazole }[9,266]\end{array}$ \\
\hline
\end{tabular}

$C N S$ central nervous system, GIT gastrointestinal tract, $I C U$ intensive care unit, $C O P D$ chronic obstructive pulmonary disease, $B A L$ bronchoalveolar lavage, CSF cerebrospinal fluid, $P C R$ polymerase chain reaction

species and may be detectable across a range of fungal infections including invasive aspergillosis, candidiasis, and cryptococcosis. Galactomannan (GM) is another commonly used marker for the diagnosis of invasive aspergillosis in patients with haematological malignancy and/or neutropenia with sensitivities and specificities of $79-96 \%$ and $74-99 \%$, respectively [23]. However, sensitivity decreases with use of antifungal agents and among non-neutropenic patients $[12,24]$. Serological testing is another option available for a range of fungal infections including candidiasis, cryptococcosis and endemic mycoses with diagnostic accuracies varying based on the type of fungal organism and sample source. While providing a good diagnostic yield for histoplasmosis and coccidioidomycosis, it is not particularly useful for the diagnosis of invasive aspergillosis [22, 28]. Polymerase chain reaction (PCR) provides an alternative, more rapid and accurate diagnostic tool for the detection of fungal infection [29]. Numerous PCR assays are described with variations in primer sequence, DNA extraction method, positivity thresholds and assay performance, which coupled with limited multi-centre clinical validation, has curtailed widespread adoption [28-31]. Importantly, false positive results are common as fungi are ubiquitous and contamination possible at various sample processing stages necessitating rigorous and costly quality control processes [32]. Next-generation sequencing (NGS) is increasingly used in epidemiological studies and during infectious disease outbreaks for resolution of species, virulence and antibiotic resistance, to assist infection control and its management [33-35]. In addition, NGS may be employed in the resolution of cryptic epidemiological cases where it has demonstrated superiority to traditional diagnostic methods in the detection of rare infections [36-38]. However, demonstration of its utility within the medical diagnostic setting is currently limited. Low abundance of fungi in relation to the overall microbial community $(\leq 0.1 \%)$ poses challenges to their detection via metagenomic sequencing in human samples, necessitating targeted amplicon sequencing approaches, which are still in their infancy 


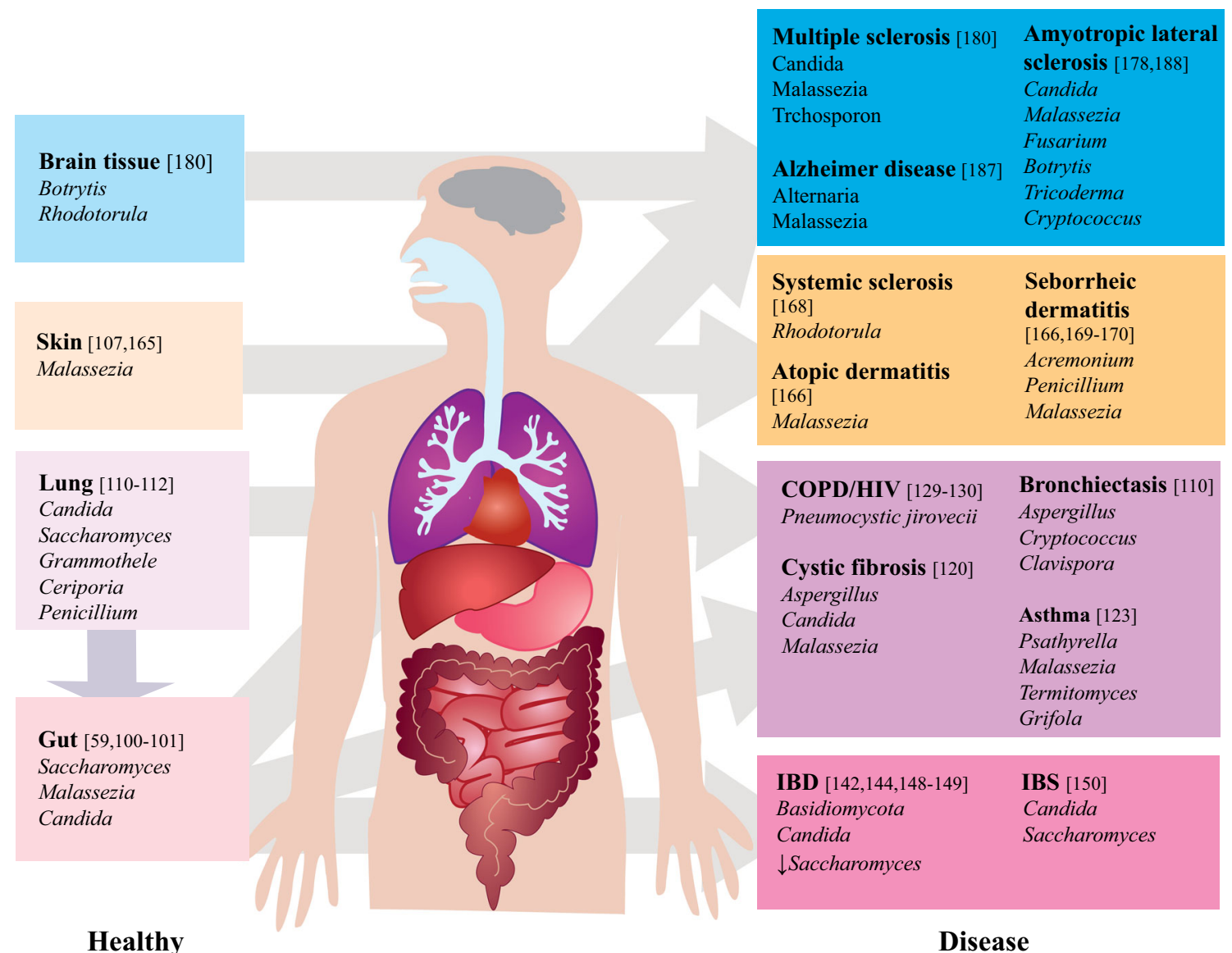

Fig. 1 Overview of the mycobiome in healthy and diseased states. Purple arrow: cross-talk between lung and gut; grey arrow: dysbiosis. COPD: chronic obstructive pulmonary

[29, 39, 40]. Further refinement and standardisation of reproducible wet-lab and bioinformatic workflows coupled to automated and scalable user-friendly reporting systems remain key challenges for the field, which unless addressed, will continue to impede widespread adoption and translation into clinical practice [41-43].

Four distinct classes of antifungal drugs are currently prescribed: the polyenes, flucytosines, azoles and echinocandins. Despite treatment, mortality rates for invasive fungal disease remain high with factors contributing to poor prognosis including delayed diagnosis and initiation of antifungal treatment, host factors, site of infection, emerging antifungal resistance and drug toxicity. Clinical presentation of fungal infection is largely non-specific, and therefore a high index of suspicion is necessary for early diagnosis and disease; HIV: human immunodeficiency virus; IBD: inflammatory bowel disease; IBS: irritable bowel syndrome; down arrow: decreased abundance

initiation of treatment, particularly in the immunocompromised population. Host factors of relevance include underlying comorbidities and long-term medications that interact with antifungal treatment. This is most marked in concomitant antifungal and antiviral treatments in HIV-related cryptococcus infection, which results in life-threatening inflammation secondary to immune reconstitution. The available tissue concentrations of antifungals also differ according to their chemical and pharmacokinetic properties leading to sub-optimal concentrations, therapeutic failure and the development of resistance in many settings, highlighting the importance of infection site to the appropriate selection of antifungal agent [44]. Drug toxicity is a further consideration as treatment is often prolonged and, in those with other comorbidities, increases the risk of drug-drug interactions [45]. 
Antifungal resistance is emerging rapidly, both intrinsic resistance and that driven by the widespread use of antifungal and environmental fungicides [46]. Resistance, however, varies based on geographic location, patient demographics and prior drug exposure [47, 48]. Azole resistance in Candida and Aspergillus spp. ranges from $2.3-40$ to $0.85-28 \%$, respectively [47, 49-52]. Resistance to echinocandins-first-line antifungal agents for invasive candidiasis-is also described in invasive Candida glabrata infections [48, 51, 53-55]. The development of new antifungals with decreased toxicity and broad-spectrum coverage is urgently required to reduce mortality rates, and a better understanding of host-fungal interaction is necessary to facilitate future therapeutic development pipelines. Furthermore, advances in NGS enable identification of antifungal resistance genes, informing our understanding of the resistome and guiding antifungal drug development [56-58]. In the following sections, we aim to describe our current understanding of the mycobiome in the context of recent NGS advances and the methodological challenges and barriers that exist in terms of its clinical implementation.

\section{Mycobiome Analysis: Methodologies and Challenges}

\section{Sample Processing}

Sample processing including storage conditions and various DNA extraction protocols may inadvertently introduce confounders that affect experimental results (Fig. 2). To date, studies comparing various methodologies of sample processing demonstrate conflicting results and varying efficacies, with implications for cross-comparisons of published mycobiome research. Freezing samples within $12 \mathrm{~h}$ to prevent overgrowth by fast-growing fungi and avoiding multiple freezethaw cycles has been advocated [59, 60]. The addition of RNAlater decreases the relative abundance of certain fungal taxa particularly in faecal samples suggesting possible introduction of bias in relative abundance assessments [61]. Nevertheless, taxonomic diversity generally remains assessable and largely unaffected by the freezing process [61-63]. When extracting fungal DNA for mycobiome sequencing, the highly rigid fungal cell wall, rich in glucans, chitin, mannans and glycoproteins, has necessitated additional steps that involve rigorous bead-beating or enzymatic lysis prior to DNA extraction [61, 62, 64-67]. Notably, enzymatic lysis provides an alternative option for increasing DNA yields [68-70]. The harsher bead-beating method, however, is observed to have conflicting efficacies likely due to DNA degradation [71]. Various DNA extraction methods also significantly affect fungal DNA yield and quality with phenol/chloroform extraction often outperforming the various available commercial kits (Fig. 2) [61, 62, 65, 70, 71]. This loss of DNA using commercial kits is likely related to use of silica column purification [71]. DNA extraction kits illustrate inconsistent results when performed with different sample types and produce variable fungal DNA yields [70, 72]. While extraction methods affect DNA yield and quality, their impact on mycobiome composition and diversity appears minor [62, 65, 71]. However, recent work from our group, using spontaneous induced sputum, has demonstrated more consistent amplification of the ITS region from samples subjected to mechanical disruption as compared to enzymatic lysis [40]. This was observed despite higher overall DNA yields achieved by enzymatic lysis suggesting preferential liberation of fungal DNA by mechanical lysis [40]. Extraction methods are critical and must be applied consistently and carefully both within and between mycobiome studies. Ultimately, sample-specific mycobiome protocols are required and a need exists to incorporate specific methods adjusted to sample type or disease-specific application, importantly, with validation for routine use in future mycobiome research.

\section{Amplicon Sequencing}

In contrast to high-throughput sequencing (HTS) of the bacterial microbiome, taxonomic classification and primer choice are not well established for the fungal mycobiome (Fig. 2) [60, 73]. As amplicon sequencing is well recognised to be subject to selective amplification bias, careful consideration of primer selection is crucial [74]. Key factors include taxonomic resolution, coverage, accuracy and amplicon length [74]. The ITS region, located between genes encoding ribosomal subunits $18 \mathrm{~S}$ and $23 \mathrm{~S}$, has been proposed as the universal genetic fungal barcode, primarily because these regions have high 
Sample collection

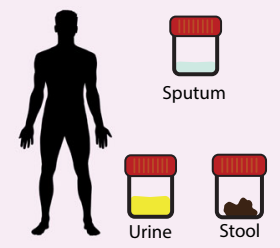

A) Different sampling method

B) Reprodubility

C) Stability with time

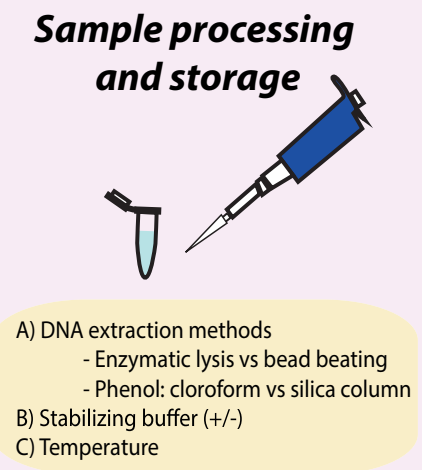

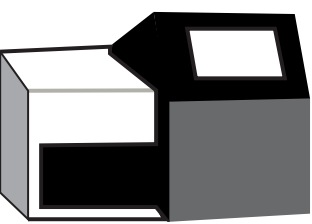

Targeted Amplicon Sequencing
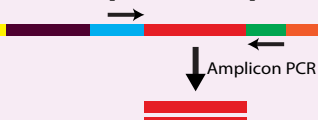

A) Primer selection (18s rRNA, ITS1, ITS2)

B) Optimal PCR amplification cycles

C) Contamination

D) Cost

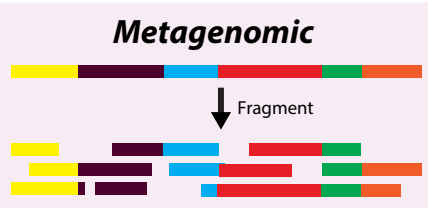

A) Low abundance of fungi relative to bacterial DNA in a variety of human samples

B) Contamination

C) Cost
Bioinformatic analysis

\section{OTUs clustering}

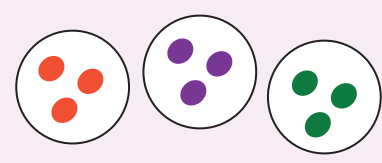

A) Lack of reference database SILVA, SSU, RDP, INSDC, UNITE, Warcup ITS.

B) Analysis pipeline

ITSx, USEARCH, PipeCraft, mothur, QIIME2, SWARM, MED,

DADAZ. PIPITS, FindFungi, BLAST, UBLAST, GhostX, DIAMOND, KAIJU, Kraken

C) Large genomic database

D) Data storage

Fig. 2 Diagram summarising the key challenges in mycobiome sequencing and analysis. PCR: polymerase chain reaction, rRNA: ribosomal ribonucleic acid, ITS: internal transcribed spacer, DNA: deoxyribonucleic acid, OTU: operational taxonomic unit

evolutionary rates and are flanked by highly conserved regions serving as suitable target sites for universal primers $[60,73,75,76]$. The ITS region typically spans 500-700 bps, and consists of two sub-regions, ITS1 and ITS2, which are separated by the conserved 5.8S region [77]. Although primers targeting ITS1 (i.e. ITS1F and ITS2) have been used for decades in several large-scale microbiome projects, to date, it is still unclear which ITS fragment is optimal. Recent findings demonstrate that these primers suffer from primer bias, amplification bias and fail to accurately profile mock communities analysed, leading to inconsistent representation of synthetic fungal communities of known taxonomic abundance [40, 74, 78-82]. Based on these observations, Nilsson and colleagues provide a list of fungus specific, HTS-oriented primers for amplification of ITS region, and recommend targeting the ITS2 sub-region by using degenerate forward primers gITS7ngs and the reverse primer ITS4ng owing to their superior coverage of the fungal kingdom [60]. Advantages of the ITS2 sub-region include a more universal primer site and lower length variation, leading to less taxonomic bias compared to ITS1 [60, 83, 84]. While this primer set (gITS7ngs and ITS4ng) has a superior coverage of fungal kingdoms, its accurate taxonomic resolution has yet to be evaluated experimentally [82]. Further confirmatory studies are required before the field can advance and eventually reach consensus on methodology for targeted amplicon sequencing of the mycobiome, as has been the case for $16 \mathrm{~s}$ rRNA sequencing of bacterial microbiomes. In addition to primer choice, care must be taken to yield fewer compromised amplicon sequences. These include careful consideration of number of PCR cycles and dilution of DNA samples where possible (Fig. 2) [85, 86]. High fidelity proofreading PCR polymerase with low GC content bias is also necessary to reduce chimeras and random errors that accumulate in later cycles [85, 86]. It is also essential to include appropriate negative controls and a mock community into the analysis. The former indicates sources of potential contamination, while the latter allows assessment of chimera formation, quantification of index switching and operational 
taxonomic unit (OTU) inference stringency (Fig. 2) $[85,87,88]$.

\section{Metagenomic Shotgun Sequencing}

An alternative approach to targeted amplicon sequencing is the use of whole-genome shotgun (WGS) metagenomics to study the mycobiome. This entails the sequencing of all extracted DNA in a given sample without the use of targeted PCR amplification of the ITS or other specific target sequences. Here, all DNA from resident microbes and host cells present in a sample is assessed. Sequence reads are processed and classified relative to a reference database through either assembly-based or assembly-free methods [89]. Analysis will usually also include steps for removal of host DNA sequences, which may contribute to a significant proportion of sequence data if removal of human cells is not attempted prior to DNA extraction [90]. While, in principle, metagenomic sequencing should provide a superior, unbiased assessment of the mycobiome, studies to date employing WGS metagenomics highlight the low abundance of fungi relative to bacterial DNA across a variety of human samples (Fig. 2) [39]. This represents a significant cost barrier given the sequencing depth therefore required to detect fungi in samples where bacteria predominate while lower sequencing coverage also hinders assembly-based analysis of fungi [89]. Currently, it appears that low fungal abundance in human samples hinders the widespread application of metagenomic WGS in human samples, a finding that appears unrelated to DNA extraction methods and reflects a genuinely low overall in vivo fungal abundance [63].

\section{Bioinformatic Challenges}

The development of tools for the analysis of ITSderived amplicon sequences is still a nascent area of research, and many options are available for the analysis of metabarcoding amplicon data sets [29]. While the field still has no consensus on standards and best practices, further studies are clearly required, and no optimal, broadly applicable protocol has been yet established. Further, it is probable that amplicon sequencing and its accompanying analysis largely depend on the samples under investigation due to variable primer coverage, as demonstrated for comparable bacterial microbiome analysis targeting the
16 s rRNA gene [91]. The increased variability of the fungal ITS region exacerbates this problem in the case of mycobiome research, and this requires careful consideration when interpreting ITS-derived mycobiome profiles. A further analytic hurdle of mycobiome metagenomic analyses remains the sparsely populated fungal databases on which read classifications are based (Fig. 2). This leads to large numbers of unclassified reads or unidentified operational taxonomic units (OTUs), which may be addressed by generation of more high-quality metagenomic and whole-fungal genome assemblies [63, 92]. Major fungal ITS reference databases include the INSDC, UNITE and Warcup ITS [60]. Although accurate species-level classification is not possible using the ITS regions, there are currently no known alternate markers offering comparable lineage separation, while reported taxonomic thresholds for filamentous fungal identification at the genus, family, order and class levels are estimated at $94.3 \%, 88.5 \%, 81.2 \%$ and $80.9 \%$, respectively $[60,93]$. The increased accessibility of third-generation long-read sequencing offers promise in this regard as the large stretches of repetitive and non-coding DNA as well as introncontaining genes found in fungal genomes can be resolved by these technologies which may also be applied to targeted sequencing of the ITS [60, 63]. Although the literature on fungal metagenomics is lacking, two key studies (Nash et al. and Donovan et al.) represent the most in-depth assessment to date in terms of metagenomic identification of fungi in human samples [63, 94]. Nash et al. performed a large assessment of gut samples from the human microbiome project, performing both metagenomic analysis and comparative ITS sequencing. Importantly, they showed that DNA extraction methods did not have appreciable effects on the levels of fungi detected, reaffirming the apparent low abundance of fungi in these samples. Secondly, they performed a comparative analysis of ITS and $18 \mathrm{~s}$ targeted sequencing protocols demonstrating that ITS2-targeting primers showed greater resolution of low-abundance taxa [63]. The work of Donovan and colleagues is notable for their bioinformatic dissection of the challenges inherent to analysis of the fungal metagenome. They present a solution in the form of the 'FindFungi' pipeline, which highlights the challenges of fungal metagenomic analysis including false positive detection, for which they developed an important step to identify uneven 
read distribution across reference genomes indicating spurious fungal detection [94]. Finally, an additional challenge that remains is the implementation of these bioinformatic pipelines, which, necessitates execution on high-performance computing clusters due to the requirement to hold large genomic databases in memory (Fig. 2). Such computation requires domain expertise that may not be widely available to fungal research laboratories and remains an operational and logistical challenge.

\section{Comparison with Culture and Other Fungal \\ Detection Methodologies}

Culture-based methods of detection require a priori selection of fungal growth conditions and are susceptible to bacterial overgrowth hindering the proliferation of selected fungi leading to bias. In addition, culture-based methods are prone to cross-contamination of spore-producing fungi, which can be minimised by the use of horizontal laminar flow clean bench $[95,96]$. While the addition of antibiotics to culture media is commonly employed to prevent bacterial contamination, its drawbacks include limited antibacterial spectrum, and its potential inhibitory effect on fungi [97-99]. Results from culture methods may be difficult to cross compare with the existing literature given heterogeneity of methodology and study designs as well as sample pre-processing protocols, thereby requiring a standardised protocol for detecting key fungal pathogens [100, 101]. However, culture-based methods do allow for an assessment of antifungal susceptibilities and the isolates obtained by culture provides scope for further molecular characterisation. Numerous culture-independent approaches have been developed to overcome the limitations of culture-based methodology but are not without their disadvantages. Internal transcribed spacer-polymerase chain reaction (ITS-PCR) approaches could be used to detect mixed infections; however, careful target selection is necessary [76, 102-104]. In some cases, ITS-PCR may appear even less reliable than culture for fungal detection [95]. Multiplex PCR assays allow for greater efficiency but require strict primer design [101]. However, PCR-based approaches are susceptible to falsenegative results where sub-optimal sample storage or DNA extraction methods are employed or where PCR inhibitors are present. The use of oligonucleotide array platforms represents a possible alternative but is expensive and subject to batch effects [101]. Arguably, sequencing of individual amplified ITS regions remains the gold standard for fungal identification, allowing for sensitive detection of unculturable or low-abundance fungi but may not be practical for all laboratories [105]. The use of mycobiome profiling as an alternative to culture-based and molecular diagnostic detection methods represents potentially valuable applications for this technology, but one that requires further validation and research [95].

\section{The Mycobiome in Health and Disease}

\section{Host-Fungal Interaction}

The term mycobiome is used to describe the fungal component of the microbiome. It is yet unclear whether a core mycobiome, analogous to the bacteriome, exists in humans [106]. Relative to the bacteriome ( $>99 \%$ of the total microbiota), the human mycobiome is less diverse (generally $<20$ OTUs per sample) and present at a lower abundance $(\leq 0.1 \%$ of the total microbiota) [39, 63]. Targeted sequencing approaches reveal that infants are colonised by fungi shortly after birth, predominantly by members of the genera Candida, Saccharomyces, Cladosporium, Cryptococcus and Malassezia [107, 108]. Where correlated, stool mycobiomes from healthy adults reveal profiles predominated by Saccharomyces, Malassezia and Candida suggesting that these genera are the key constituents of a healthy mycobiome throughout life. Critically, however, and in contrast to human bacteriome studies, little correlation with host phenotype metadata is firmly established in healthy individuals and, as such, our knowledge of fungal mycobiome-host interaction remains limited to that in fungal colonisation and/or disease. It is clear from existing studies and their subsequent molecular analysis that intricate immunological systems have evolved to regulate fungal homoeostasis and, when perturbed, lead to infection or other pathologies [109]. Immunity to fungi is underpinned by innate signalling pathways recognising both spores and fungal cell wall components and include adaptive $\mathrm{T}$ cell responses that orchestrate tolerance and appropriate immune surveillance of ubiquitous fungi encountered daily $[109,110]$. Immune responses to fungi are protective 
when functioning, however, where over-zealous, can manifest as allergy. Consequently, the evolution of immuno-regulatory mechanisms in vivo is perturbed across a range of fungal-driven allergy. Given the parallels with the human bacteriome, where host immunity acts as gatekeeper, it is arguable that similar ecological interactions occur with fungi [111]. Perhaps the strongest evidence for a conserved human mycobiome is evidenced by the restricted numbers of fungi that actually inhabit the human body, suggestive of niche specialisation [112]. Despite over 50 described bacterial phyla, the human bacteriome is characterised by four: Actinobacteria, Bacteroidetes, Firmicutes and Proteobacteria. In corollary, fungal taxa exhibit lower diversity in vivo compared to that seen environmentally and associations between fungi and specific body sites indicate the likely existence of selection and adaptation [113, 114]. Given the limited available data, formal meta-analysis of clinical mycobiome studies, while important, is currently challenging to perform. However, emerging associations based on culture-independent mycobiome studies in humans are summarised in Fig. 1.

\section{The Lung Mycobiome}

While fungal lung disease is now widespread and a growing global concern, the lack of dedicated mycobiome studies assessing the effects of fungi in chronic lung disease is hampering the field. In this particular organ system, the prior presupposition of sterility in a healthy lung puts back microbiome studies in this area for a number of years, and consequently, our understanding of the respiratory microbiome lags significantly behind that at other anatomical sites [115]. The advent of culture-independent sequencing technologies has uncovered the diversity of organisms inhabiting the lung, including that in the healthy state $[116,117]$. Through the use of internal transcribed spacer (ITS) sequencing, it was reported that Ceriporia lacerata, Saccaromyces cerevisiae and Penicillium brevicompactum were possible pulmonary fungi, with the main pathogen being Aspergillus fumigatus [118, 119]. Lung-dwelling microbiota include bacteria, fungi and viruses, which together maintain a crosskingdom ecological network [120]. Interactions between lung and gut microbiomes, through the lung-gut axis, have further immunological consequence, and changes in the gut mycobiome can influence allergic airway disease [121-125]. The healthy lung mycobiome differs from that observed in patients suffering with chronic inflammatory respiratory disease such as asthma, chronic obstructive pulmonary disease (COPD), cystic fibrosis (CF) and bronchiectasis [126, 127]. The lungs in asthma, COPD and $\mathrm{CF}$ all exhibit lower fungal diversity, which in turn is linked to poorer lung function postulated to be influenced by fungal overgrowth and/or loss of some fungal species [128]. In asthma, higher loads with increase percentages of Psathyrella candolleana, Malassezia pachydermatis, Termitomyces clypeatus and Grifola sordulenta and a greater fungal diversity were observed compared to that of a healthy airway [129, 130]. In children with severe asthma, a higher abundance of Rhodosporidium, Pneumocystis, Leucosporidium and Rhodotorula was detected when compared to those without asthma [131]. Bronchiectasis, a permanent and irreversible dilatation of airways, places patients at the higher risks of fungal acquisition and colonisation [132]. This is reflected by airway mycobiomes demonstrating a higher abundance of potentially pathogenic taxa including Aspergillus, Penicillium and Cryptococcus and the detection, in many patients, of an unfavourable allergic sensitisation and immune response profile associated with Aspergillus [117, 133]. In view of the dysfunctional mucociliary clearance inherent in bronchiectasis, the airway is susceptible to inhaled airborne fungi and therefore colonisation [134]. In COPD, Aspergillus spp. has been isolated in $17 \%$ of patients and particular fungal taxa such as Pneumocystis jirovecii associated with a COPD airway have also been found in HIV and COPD-associated HIV suggestive of immunological predisposition $[135,136]$. The overrepresentation of Pneumocystis and other fungal species in HIV-related COPD further illustrates the relationship between fungal communities in the lung and corresponding lung function and homoeostasis, warranting more detailed investigation by culture-independent sequencing [137]. Significant fungal variability is seen in cystic fibrosis (CF), a genetic disease caused by abnormal Cystic Fibrosis Transmembrane conductance Regulator (CFTR) function, where fungal colonisation and infection for $A$. fumigatus range between 6 and 60\% [138]. While dedicated CF mycobiome research is nascent, a number of groups have nevertheless started to characterise its main components. Stable fungal 
communities are detected and exist in parallel to the more ephemeral fungal species that remain transient when assessed longitudinally [95, 127, 128, 139-143]. Targeted sequencing studies of the $\mathrm{CF}$ mycobiome reveal that in addition to the fungi detected by mycological culture alone, that (unculturable) fungal taxa are also present [95, 139, 142]. Overall, an increased abundance of Aspergillus species (particularly A. fumigatus), C. albicans, C. parapsilosis and Malassezia is identified [127]. In both asthma and CF, an allergic response may be induced when Aspergillus is encountered, with the key form being allergic bronchopulmonary aspergillosis (ABPA) [144]. The application of mycobiome sequencing approaches to the lung has started to gain significant traction and research interest with the transition from smaller pilotscale optimisation studies to a more detailed and comprehensive assessment in well-phenotyped cohorts of patients with respiratory disease [117, 139, 145, 146].

\section{The Gut Mycobiome}

Efforts to examine gut mycobiomes have largely focused on gastrointestinal (GI)-associated disease, and key findings echo trends of mycobiome alteration in other non-GI diseased states. In inflammatory bowel disease (IBD), for instance, initial work using $18 \mathrm{~S}$ rRNA and rDNA sequencing showed an increased fungal diversity in Crohn's disease (CD) but not ulcerative colitis (UC) [147, 148]. Further differences were also identified between inflamed and noninflamed tissue [147]. More recently, however, application of ITS2 sequencing has found distinct fungal microbial dysbiosis in IBD with increased Basidiomycota/Ascomycota ratios accompanied by higher proportions of $C$. albicans but reduced levels of $S$. cerevisiae [149]. In CD, ITS2 pyrosequencing also confirms increases to overall fungal load during disease flares and a higher prevalence of the Cystofilobasidiaceae family and C. glabrata species. In correlation, the application of ITS1 sequencing in another study revealed an increased Candida tropicalis in CD as compared to non-CD relatives [150]. Interestingly, S. cerevisiae and Filobasidium uniguttulatum are associated with non-inflamed tissue in CD [151]. Malassezia restricta was found to increase CD severity in a subset of patients with $C A R D 9$ polymorphisms, suggesting that the targeting of specific fungi in certain patient phenotypes may have value [152]. It is further demonstrated that antifungal drugs lead to increases in colitis severity in animal models where ITS1 amplicon sequencing revealed gut fungal dysbiosis characterised by a reduction in Candida spp. and concurrent increase in Aspergillus, Wallemia and Epicoccum spp. [153]. Similarly, antibiotics influence gut inflammation through modification of the gut bacteriome with a consequential impact on fungal colonisation [154]. Here, alteration in Enterobacteriaceae modulates fungal colonisation and colitis severity [154]. Although the mouse gut mycobiome does not fully represent that in humans, these findings lend support to the implication of fungal dysbiosis in IBD. Paediatric IBD has also been assessed providing insight into potential age-associated effects, and $18 \mathrm{~S}$ rDNA pyrosequencing illustrates Basidiomycota dominance [155]. In other paediatric IBD works, ITS1 pyrosequencing reveals high Candida burdens and a reduced fungal diversity [156]. While dedicated study of the healthy gut mycobiome is limited and much required, Nash et al. observed the healthy human gut mycobiome to be lacking in diversity and dominated by yeast genera such as Saccharomyces, Malassezia and Candida, albeit with significant interand intra-individual variability [63]. This suggests active and dynamic change to the gut mycobiome over time, further influenced by host immunity, even in the absence of disease. In Irritable Bowel Syndrome (IBS), a functional gastrointestinal disease, ITS1based metabarcoding of faecal samples reveals a gut mycobiome dysbiosis with a significant loss of diversity. Saccharomyces and Candida were dominant in IBS and healthy controls, but higher proportions were observed in the former [157]. Visceral hypersensitivity is linked to IBS with fungi implicated in animal models, suggesting that targeted manipulation of the mycobiome may provide scope for therapeutic intervention [158, 159]. Mycobiome signatures clearly differ between hypersensitive and normally sensitive IBS [158]. While these findings are clearly of clinical interest, more compelling evidence and biological validation is required to further clarify mechanistic underpinnings of these early observations [157]. Interestingly, in the oncological setting, antifungal treatment is associated with decreased tumour progression in pancreatic ductal carcinoma, while posttherapeutic repopulation by Malassezia accelerates tumour growth [160]. In addition, an increased 
abundance of Malassezia is described in colorectal cancer by faecal shotgun metagenomic sequencing, along-with Moniliophthtora, Rhodotorula, Acremonium, Thielaviopsis and Pisolithus, while a higher abundance of Basidiomycota is associated with more advance disease [161, 162]. The gut mycobiome may additionally influence other organ systems such as the lung and central nervous system through their respective axes, but the precise mechanisms are poorly understood. In particular, the lung-gut axis, which includes the mycobiome, is highlighted as a key and emerging player in determining susceptibility to chronic lung disease, and the gut microbiome composition in itself has also been independently associated with several chronic inflammatory lung diseases [118]. For instance, the presence of C. albicans in the gut influences Th17-related immune pathways, which in turn has implications for Aspergillus-associated pathology in chronic airways disease supporting a role for lung-gut cross-talk in the pathogenesis of respiratory disease [124]. Gut mycobiome dysbiosis is reported in multiple neurological disorders, where a higher abundance of Candida occurs in schizophrenia, autism and Rett Syndrome [163-166]. This has prompted the investigation of gut fungi in the microbiome-gut-brain axis, an emerging biological concept already firmly established with respect to bacteria [167]. While recent studies describe associations between fungal dysbiosis and IBS, the association with neurological symptoms such as anxiety and depression in IBS sufferers is intriguing, results that further support the role of gut fungi in the microbiome-gut-brain axis [168]. While these findings remain speculative at present requiring more study to explain clearer biological mechanism, they nevertheless do illustrate the importance and emergence of the fungal mycobiome in human disease.

\section{The Skin Mycobiome}

The skin remains a key organ and provides barrier protection against pathogens but is also home to resident fungi [169, 170]. Different skin components demonstrate differing fungal patterns, and fungal species also vary by age and gender. For instance, children have greater numbers and variety of fungi on their skin compared to adults, who are dominated by lipophilic Malassezia [115, 171]. This is likely explained by the changes in sebum composition and sebaceous gland activation [171]. Most work reveals that healthy skin (across many body sites) is characterised by Malassezia, which produces an aryl hydrocarbon receptor (Ahr) ligand beneficial for epithelial cell health and UV protection [114, 115, 172]. Diverse domains of the skin mycobiome interact with one another, promoting connectivity and providing network stability. Comparable to lung mycobiomes, the communities in skin mycobiomes help maintain ecological network structure [120]. As with other organ systems and their microbiomes, the skin mycobiome associates with skin disease: Malassezia, when in higher abundance or where an inappropriate immune response is observed is seen in association with seborrhoeic or atopic dermatitis [115, 173]. Conversely in psoriasis, which involves the multiplication of skin cells at much higher rates, patients had a lower abundance of Malassezia when compared to healthy skin despite Malassezia remaining the dominant phylum in both groups [174]. Relationships between the skin mycobiome and systemic diseases demonstrating dermatological manifestations are established: for example, the role of fungi in systemic sclerosis (SSc), an autoimmune disease characterised by skin thickening where Rhodotorula glutinis is highly abundant. Average $R$. glutinis abundance in normal subjects compared to SSc patients was 0.02 and 5.04 per million reads, respectively, supporting this association [175]. Tinea versicolor (Pityriasis versicolor), a skin fungal infection, attributed to Malassezia and a consequence of Malassezia protein-induced melanocyte apoptosis and UV exposure has also been the subject of multiple investigations [115]. Affected lesions illustrate high burdens of $M$. globosa, M. sympodialis and M. furfur, and mycelial fungal forms predominate in contrast to yeast forms commonly seen in healthy skin [176]. A role for the mycobiome has been established in seborrhoeic dermatitis, a condition where scaly patches, red skin and persistent dandruff ensue. While Ascomycota and Basidiomycota are prevalent in both healthy and dandruff-affected human scalps, the latter illustrates higher densities of Acremonium, Penicillium and Malassezia [176, 177]. Malassezia restricta and Malassezia globosa are identified in seborrhoeic dermatitis, and the presence of new colonising strains when compared to the healthy scalp is indicative of disease onset [173]. Malassezia may also more directly cause dandruff as antifungal agents are 
particularly effective as treatment [176]. Atopic dermatitis (AD) (eczema) is another important skin condition with established mycobiome associations: significant intra- and inter-individual variation is observed in AD where taxonomic diversity has been examined. However, consistently, as is the case in other skin conditions, $M$. sympodialis, $M$. sloofiae and $M$. dermatis all characterise disease and sometimes exacerbate it. AD patients demonstrate circulating IgE to Malassezia and on closer examination, secreted Malassezia vesicles from AD patients differ in their RNA content when compared to healthy individuals [115, 176, 178-180]. In addition, Malassezia may induce cutaneous inflammation via a Th-17 response, with increased CCR6 + Th17 memory T cells $(M$. specific) observed in AD [181]. While Malassezia is a key AD correlate, it is important to recognise that nonMalassezia fungi are also described [179]. Different methodologies have been employed to characterise and describe skin mycobiomes: ion-torrent sequencing has been used in $\mathrm{AD}$, while other approaches include targeted amplicon sequencing of various fungal regions, such as the fungal $28 \mathrm{~S}$ rRNA large subunit D1/D2 and the 18S rRNA, internal transcribed spacer (ITS) regions ITS1 and ITS2 [108, 114, 171, 173, 175, 176, 179, 182-184].

The Mycobiome and Neurological Disorders

Increasing evidence suggests the importance of the microbiome in neurological disease. Changes to gut bacteria are linked to multiple sclerosis (MS), a neuroinflammatory disease characterised by demyelination and neurodegeneration, suggesting cross-talk via gutbrain microbiota in its pathogenesis [185-190]. Higher abundance of Candida, Malassezia and Trichosporon by targeted ITS1 sequencing is reported in MS compared to control brain tissue [187]. Similarly, metagenomic analyses of cerebrospinal fluid (CSF) from MS patients reveal that the presence of Malassezia, Ascomycota, Funneliformis, Glomus, Cladosporium, Candida and Alternaria, however as concluded by these works, likely reflects environmental contaminants [191]. In contrast, Jovel et al. using CSF from MS patients did not report any detection of fungal reads [192]. In Alzheimer's disease, fungal cells are detected in neurons through immunohistochemistry and confocal microscopy within brain tissue and these fungal species are further identified by nested PCR, where Candida, Cladosporium, Malassezia, Neosartorya, Phoma and Sacharomyces are detected [193]. Using targeted amplicon sequencing, Alternaria and Malassezia are higher in Alzheimer's compared to normal brain tissue [194]. In other works, brain tissue from individuals with amyotrophic lateral sclerosis (ALS), a neurodegenerative disease with progressive motor neuron dysfunction, contains an increased abundance of Candida, Malassezia, Fusarium, Botrytis, Trichoderma and Cryptococcus $[185,195]$. The strong association between seborrhoeic dermatitis and Parkinson disease (PD) also raises the suspicion of specific Malassezia contribution to both disease states. Importantly, genetic polymorphisms associated with PD and levodopa use are known to promote Malassezia growth and invasiveness, and hence this fungal association is of clinical relevance [196]. Collectively, these studies implicate fungi in the pathogenesis of several neurological diseases underlining the importance of fungal biology and host-microbe interaction to overall human health and the inter-organ axis communication networks posited to promote disease onset.

The Environmental Mycobiome

Fungi are ubiquitous and present in indoor (built) and outdoor environments [197]. While indoor and outdoor fungal communities are similar, indoor fungal particles are passively distributed and dominated by spores, hyphal fragments and other dormant fungi [198]. Fungi from indoor air may originate from outdoor air with air exchanges when windows are opened [199]. Outdoor airborne fungal composition is affected by location, temperature and humidity, with large numbers of fungi identified by metagenomic sequencing, with consequent and significant impact on indoor fungal communities [200]. Other sources of indoor fungi include humans, pets, plants, plumbing systems, heating ventilation and air conditioning systems (HVAC), and also dust re-suspension [201, 202]. Exposure to indoor fungi and fungal particles is linked to health-related outcomes including allergies, fatigue and asthma [197, 203]. In addition, damp dwellings pose an additional health risk due to fungal exposure [204]. The built mycobiome is therefore of interest from microbiological, environmental and clinical perspectives. Traditionally, morphology-based studies of fungal cultures and 
their spores, derived from indoor sampling, have recognised many common indoor fungal species; however, with the application of high-throughput sequencing in the built environment, the much larger scale and depth of the indoor fungal diversity have been demonstrated [203, 205]. Using pyrosequencing of ITS2 and D1/D2 of the large ribosomal subunit (LSU), Amend et al. recovered approximately 4400 fungal OTUs at the species level in a global study of indoor dust samples, while Nonnenmann et al. applied the combination of quantitative PCR with the fungal tag-encoded flexible amplicon pyrosequencing technique and describe 450 fungal species from fifty indoor dust samples in the Yakima valley, WA (USA) [206, 207]. In other works, 986 fungal OTUs were detected in a homogeneous set of houses in a Californian family housing complex [199]. Considering culture-dependent and culture-independent approaches (including next-generation sequencing; NGS), substantial fungal diversity is now associated with the built environment. These indoor fungi, whether persistent residents or transient visitors, likely hold clues to the increasing numbers of human allergies and other health problems observed globally in previously healthy individuals [208]. One such example is 'sick building syndrome': associated with poor indoor air quality and fungal exposure and experienced by building occupants, with symptoms including headache, dizziness, nausea, eye, nose or throat irritation [209-211]. As part of the effort in reducing harmful exposure of indoor fungi, sourcetracking of airborne fungi is necessary to locate and eliminate contaminated building surfaces that may serve as potential reservoirs, a major challenge given the highly dynamic movement of aerosols. Fungal growth on building surfaces may also be invisible to the naked eye, and it is impractical to swab all surfaces for examination. Therefore, future studies must instead attempt source-tracking by swabbing potential source surfaces in homes, classrooms and offices to compare them against air samples using probabilistic models [201, 212]. Some early works have reported mould and yeasts from the genera Alternaria, Aspergillus, Cladosporium, Penicillium, Rhodotorula and Wallemia, where Rhodotorula mucilaginosa generally dominate moist spaces such as toilets, $A$. fumigatus in drier spaces such as the living rooms and Cladosporium in almost every living space [212, 213]. Besides source-tracking, engineered building materials and surface coatings that prevent or minimise fungal colonisation are another area of active research [214, 215]. These solutions, however, are expensive, and it is almost impossible to maintain sterility in a built environment unless medically warranted, for example, in the intensive care units of healthcare facilities, which in themselves poses a challenge [216]. Alternatively, buildings should be constructed using sustainable fungal-resistant materials complemented with architectural designs that consider operating factors such as heating, ventilation and air conditioning (HVAC) systems for controlling indoor temperature and relative humidity, as well as plumbing designs with accessible sites for addressing water leaks, all of which can contribute to a safer indoor environment, minimal fungal contamination and potentially improved human health outcomes.

\section{Translation of Mycobiome Research to Clinical Practice}

The number of reported microbiome-related publications has increased exponentially in recent years and now includes numerous studies of the mycobiome [94, 185]. In parallel, a better understanding of the role of microbes in health and disease has emerged with studies increasingly investigating the importance of the mycobiome and its contribution to disease [117, 124, 133, 217-219]. It is likely that these organisms co-exist in the same environment and that interaction between bacterial, fungal and viral microbiomes achieves homoeostasis among healthy individuals, while dysbiosis leads to disease. Although increasingly investigated in association with pathological states, it is still too early to make conclusions about the true clinical importance and relevance of the mycobiome. Several challenges do remain including the validation and standardisation of robust sampling and analytic methodologies, which must be examined in larger-scale studies. Currently, there is no standardised method in mycobiome sequencing with variation in DNA extraction methods, primer selection, sequencing, reference databases and analytical pipelines (Fig. 2), precluding robust meta-analysis of clinical studies performed to date, which continue to increase, but remain limited in number. Nevertheless, the field of mycobiome research is evolving and the rapid adoption of sequencing and computational technologies may overcome current limitations and 
allow a better definition of the mycobiome from a clinical context [29]. With an improved understanding of resident mycobiomes and their interaction with host immunity, as correlated with disease at difference stages, this potentially opens avenues for early diagnosis and more targeted therapeutic approaches. Moreover, the use of NGS to characterise resistome pathways may have relevance for surveillance, antifungal stewardship and the development of new antifungal drug approaches. Newer treatment approaches may emerge from better patient stratification based on mycobiome profiles, while manipulating or restoring a 'healthy' mycobiome also represents a potentially viable approach for precision medicine. These technological advancements combined with sequencing and analysis may be simplified and evolve into point of care diagnostics for fungal disease in the future.

\section{Future Directions}

The number of microbiome studies focused on bacteria far exceeds that of the fungal mycobiome (and virome). This is largely attributed to pioneering efforts towards the standardisation of methodologies for bacterial $16 \mathrm{~s}$ rRNA gene sequencing and analysis, allowing scalability. A standardised and reliable method of mycobiome sequencing combined with more comprehensive fungal database coverage is crucial to achieve similar scalability for fungal microbiomes [29, 92]. Despite known interaction between various microbes, studies integrating bacterial microbiomes, fungal mycobiomes, viromes and parasites are limited. Interaction between members of microbial kingdoms likely results in an alteration of function and behaviour of individual microbes, which in turn play important roles for disease pathogenesis. Microbes housed at key body sites exhibit cross-talk and interaction with host immunity resulting in systemic manifestations of disease outside the initial site of dysbiosis. Dysregulation of intestinal microbiome has been implicated in allergic airways disease, with increased intestinal Clostridium spp. in asthmatics and an emerging role for the gut mycobiome in regulating fungal airway responses through the lunggut axis [118, 124, 220-222]. Such insight provides explanations for clinical phenomena including how disruption of the healthy intestinal mycobiome composition with oral antifungals can lead to exacerbations of allergy airway disease [173]. Changes in the composition of intestinal microbiota are also implicated in diseases of the central nervous system including autism spectrum disorder, Parkinson disease and schizophrenia, further substantiating the key role of microbiome cross-talk, which is likely to include major fungal in addition to established bacterial players $[165,223,224]$. To better understand the precise role of the mycobiome and its contribution to disease pathogenesis, future studies must assess interactions between the various microbial kingdoms in tandem with host immunity across multiple body sites in a holistic systems-based approach. Across such complex and interlinked microbial systems, the mycobiome is clearly a recognised and emerging factor that contributes to a range of diseases and their pathogenesis, which if harnessed appropriately can represent an opportunity, one that improves disease prognosis and future approaches to precision medicine using the microbiome.

Acknowledgements The authors would like to acknowledge The Academic Respiratory Initiative for Pulmonary Health (TARIPH) for collaboration support.

Author Contribution PYT and MMA contributed to conception, literature review, final manuscript writing and editing, NABMA contributed to literature review, manuscript writing, drawing of figures; KT, KG and KL contributed to literature review, manuscript writing, SHC contributed to conception, literature review, manuscript writing and editing.

Funding This research is supported by the Singapore Ministry of Health's National Medical Research Council under its Research Training Fellowship (NMRC/Fellowship/0049/2017) (P.Y.T) and a Clinician-Scientist Individual Research Grant (MOH-000141) (S.H.C); the Singapore Ministry of Education under its Singapore Ministry of Education Academic Research Fund Tier 1 (2016-T1-001-050) (S.H.C); the NTU Integrated Medical, Biological and Environmental Life Sciences (NIMBELS), Nanyang Technological University, Singapore [NIM/03/2018] (S.H.C) and the Ageing Research Institute for Society and Education (ARISE), Nanyang Technological University, Singapore [ARISE/2017/6] (S.H.C).

\section{Compliance with Ethical Standards}

Conflict of interest The authors declare that they have no conflict of interest. 


\section{References}

1. Stop neglecting fungi. Nat Microbiol. 2017;2:17120.

2. Bongomin F, Gago S, Oladele RO, Denning DW. Global and multi-national prevalence of fungal diseases-estimate precision. J Fungi (Basel). 2017;3(4):57.

3. Garcia-Solache MA, Casadevall A. Global warming will bring new fungal diseases for mammals. MBio. 2010;1(1):1-3.

4. Garber G. An overview of fungal infections. Drugs. 2001;61(Suppl 1):1-12.

5. Meyer KC, Raghu G, Baughman RP, Brown KK, Costabel $\mathrm{U}$, du Bois RM, et al. An official American Thoracic Society clinical practice guideline: the clinical utility of bronchoalveolar lavage cellular analysis in interstitial lung disease. Am J Respir Crit Care Med. 2012;185(9):1004-14.

6. Park BJ, Sigel K, Vaz V, Komatsu K, McRill C, Phelan M, et al. An epidemic of coccidioidomycosis in Arizona associated with climatic changes, 1998-2001. J Infect Dis. 2005;191(11):1981-7.

7. Byrnes EJ 3rd, Bildfell RJ, Frank SA, Mitchell TG, Marr KA, Heitman J. Molecular evidence that the range of the Vancouver Island outbreak of Cryptococcus gattii infection has expanded into the Pacific Northwest in the United States. J Infect Dis. 2009;199(7):1081-6.

8. Perlin DS, Rautemaa-Richardson R, Alastruey-Izquierdo A. The global problem of antifungal resistance: prevalence, mechanisms, and management. Lancet Infect Dis. 2017;17(12):e383-92.

9. Limper AH, Adenis A, Le T, Harrison TS. Fungal infections in HIV/AIDS. Lancet Infect Dis. 2017; 17(11):e334-43.

10. Barnes RA. Early diagnosis of fungal infection in immunocompromised patients. J Antimicrob Chemother. 2008;61(Suppl 1):i3-6.

11. De Pauw B, Walsh TJ, Donnelly JP, Stevens DA, Edwards $\mathrm{JE}$, Calandra T, et al. Revised definitions of invasive fungal disease from the European Organization for Research and Treatment of Cancer/Invasive Fungal Infections Cooperative Group and the National Institute of Allergy and Infectious Diseases Mycoses Study Group (EORTC/MSG) Consensus Group. Clin Infect Dis. 2008;46(12):1813-21.

12. Zhou W, Li H, Zhang Y, Huang M, He Q, Li P, et al. Diagnostic value of galactomannan antigen test in serum and bronchoalveolar lavage fluid samples from patients with nonneutropenic invasive pulmonary aspergillosis. J Clin Microbiol. 2017;55(7):2153-61.

13. Duarte RF, Sanchez-Ortega I, Cuesta I, Arnan M, Patino B, Fernandez de Sevilla A, et al. Serum galactomannan-based early detection of invasive aspergillosis in hematology patients receiving effective antimold prophylaxis. Clin Infect Dis. 2014;59(12):1696-702.

14. Nguyen MH, Jaber R, Leather HL, Wingard JR, Staley B, Wheat $\mathrm{LJ}$, et al. Use of bronchoalveolar lavage to detect galactomannan for diagnosis of pulmonary aspergillosis among nonimmunocompromised hosts. J Clin Microbiol. 2007;45(9):2787-92.
15. Clancy CJ, Nguyen MH. Finding the "missing 50\%" of invasive candidiasis: how nonculture diagnostics will improve understanding of disease spectrum and transform patient care. Clin Infect Dis. 2013;56(9):1284-92.

16. Simoneau E, Kelly M, Labbe AC, Roy J, Laverdiere M. What is the clinical significance of positive blood cultures with Aspergillus sp. in hematopoietic stem cell transplant recipients? A 23 year experience. Bone Marrow Transpl. 2005;35(3):303-6.

17. Tarrand JJ, Lichterfeld M, Warraich I, Luna M, Han XY, May GS, et al. Diagnosis of invasive septate mold infections. A correlation of microbiological culture and histologic or cytologic examination. Am J Clin Pathol. 2003;119(6):854-8.

18. Sloand E, Laughon B, Armstrong M, Bartlett MS, Blumenfeld W, Cushion M, et al. The challenge of Pneumocystis carinii culture. J Eukaryot Microbiol. 1993;40(2):188-95.

19. Liu Y, Fahle GA, Kovacs JA. Inability to culture Pneumocystis jirovecii. MBio. 2018;9(3):e00939-18.

20. Kami M, Murashige N, Fujihara T, Sakagami N, Tanaka Y. The mechanism for low yield of blood culture in invasive aspergillosis; the clinical importance of antigen detection tests revisited. Bone Marrow Transpl. 2005;36(1):85-6.

21. Denning DW, Kibbler CC, Barnes RA. British Society for Medical M. British Society for Medical Mycology proposed standards of care for patients with invasive fungal infections. Lancet Infect Dis. 2003;3(4):230-40.

22. Limper AH. Clinical approach and management for selected fungal infections in pulmonary and critical care patients. Chest. 2014;146(6):1658-66.

23. Wheat LJ. Approach to the diagnosis of invasive aspergillosis and candidiasis. Clin Chest Med. 2009;30(2):367-77.

24. Ullmann AJ, Aguado JM, Arikan-Akdagli S, Denning DW, Groll AH, Lagrou K, et al. Diagnosis and management of Aspergillus diseases: executive summary of the 2017 ESCMID-ECMM-ERS guideline. Clin Microbiol Infect. 2018;24(Suppl 1):e1-38.

25. Alexander BD, Smith PB, Davis RD, Perfect JR, Reller LB. The $(1,3)$ \{beta\}-D-glucan test as an aid to early diagnosis of invasive fungal infections following lung transplantation. J Clin Microbiol. 2010;48(11):4083-8.

26. Koo S, Bryar JM, Page JH, Baden LR, Marty FM. Diagnostic performance of the $(1 \rightarrow 3)$-beta-D-glucan assay for invasive fungal disease. Clin Infect Dis. 2009;49(11):1650-9.

27. Racil Z, Kocmanova I, Lengerova M, Weinbergerova B, Buresova L, Toskova M, et al. Difficulties in using 1,3\{beta\}-D-glucan as the screening test for the early diagnosis of invasive fungal infections in patients with haematological malignancies-high frequency of falsepositive results and their analysis. J Med Microbiol. 2010;59(Pt 9):1016-22.

28. Arvanitis M, Anagnostou T, Fuchs BB, Caliendo AM, Mylonakis E. Molecular and nonmolecular diagnostic methods for invasive fungal infections. Clin Microbiol Rev. 2014;27(3):490-526. 
29. Consortium O, Gabaldon T. Recent trends in molecular diagnostics of yeast infections: from PCR to NGS. FEMS Microbiol Rev. 2019;43(5):517-47.

30. Pappas PG, Kauffman CA, Andes DR, Clancy CJ, Marr $\mathrm{KA}$, Ostrosky-Zeichner L, et al. Clinical practice guideline for the management of candidiasis: 2016 update by the Infectious Diseases Society of America. Clin Infect Dis. 2016;62(4):e1-50.

31. Morton CO, White PL, Barnes RA, Klingspor L, CuencaEstrella M, Lagrou K, et al. Determining the analytical specificity of PCR-based assays for the diagnosis of IA: What is Aspergillus? Med Mycol. 2017;55(4):402-13.

32. Khot PD, Fredricks DN. PCR-based diagnosis of human fungal infections. Expert Rev Anti Infect Ther. 2009;7(10):1201-21.

33. Snitkin ES, Zelazny AM, Thomas PJ, Stock F, Group NCS, Henderson DK, et al. Tracking a hospital outbreak of carbapenem-resistant Klebsiella pneumoniae with wholegenome sequencing. Sci Transl Med. 2012;4(148):148ra16.

34. Lewis T, Loman NJ, Bingle L, Jumaa P, Weinstock GM, Mortiboy D, et al. High-throughput whole-genome sequencing to dissect the epidemiology of Acinetobacter baumannii isolates from a hospital outbreak. J Hosp Infect. 2010;75(1):37-41.

35. Weterings V, Zhou K, Rossen JW, van Stenis D, Thewessen E, Kluytmans J, et al. An outbreak of colistinresistant Klebsiella pneumoniae carbapenemase-producing Klebsiella pneumoniae in the Netherlands (July to December 2013), with inter-institutional spread. Eur J Clin Microbiol Infect Dis. 2015;34(8):1647-55.

36. Wilson MR, Naccache SN, Samayoa E, Biagtan M, Bashir $\mathrm{H}, \mathrm{Yu} \mathrm{G}$, et al. Actionable diagnosis of neuroleptospirosis by next-generation sequencing. $\mathrm{N}$ Engl $\mathrm{J}$ Med. 2014;370(25):2408-17.

37. Thoendel MJ, Jeraldo PR, Greenwood-Quaintance KE, Yao JZ, Chia N, Hanssen AD, et al. Identification of prosthetic joint infection pathogens using a shotgun metagenomics approach. Clin Infect Dis. 2018;67(9):1333-8.

38. Wilson MR, O'Donovan BD, Gelfand JM, Sample HA, Chow FC, Betjemann JP, et al. Chronic meningitis investigated via metagenomic next-generation sequencing. JAMA Neurol. 2018;75(8):947-55.

39. Qin J, Li R, Raes J, Arumugam M, Burgdorf KS, Manichanh $\mathrm{C}$, et al. A human gut microbial gene catalogue established by metagenomic sequencing. Nature. 2010;464(7285):59-65.

40. Ali N, Mac Aogain M, Morales RF, Tiew PY, Chotirmall $\mathrm{SH}$. Optimisation and benchmarking of targeted amplicon sequencing for mycobiome analysis of respiratory specimens. Int J Mol Sci. 2019;20(20):4991.

41. Fricke WF, Rasko DA. Bacterial genome sequencing in the clinic: bioinformatic challenges and solutions. Nat Rev Genet. 2014;15(1):49-55.

42. Lawlor B, Walsh P. Engineering bioinformatics: building reliability, performance and productivity into bioinformatics software. Bioengineered. 2015;6(4):193-203.

43. Walsh P, Carroll J, Sleator RD. Accelerating in silico research with workflows: a lesson in simplicity. Comput Biol Med. 2013;43(12):2028-35.
44. Felton T, Troke PF, Hope WW. Tissue penetration of antifungal agents. Clin Microbiol Rev. 2014;27(1):68-88.

45. Gubbins PO, Amsden JR. Drug-drug interactions of antifungal agents and implications for patient care. Expert Opin Pharmacother. 2005;6(13):2231-43.

46. Verweij PE, Snelders E, Kema GH, Mellado E, Melchers WJ. Azole resistance in Aspergillus fumigatus: a side-effect of environmental fungicide use? Lancet Infect Dis. 2009;9(12):789-95.

47. Rivero-Menendez O, Alastruey-Izquierdo A, Mellado E, Cuenca-Estrella M. Triazole resistance in Aspergillus spp.: a worldwide problem? J Fungi (Basel). 2016;2(3):21.

48. Wiederhold NP. Antifungal resistance: current trends and future strategies to combat. Infect Drug Resist. 2017;10:249-59.

49. Lockhart SR, Iqbal N, Cleveland AA, Farley MM, Harrison $\mathrm{LH}$, Bolden $\mathrm{CB}$, et al. Species identification and antifungal susceptibility testing of Candida bloodstream isolates from population-based surveillance studies in two U.S. cities from 2008 to 2011. J Clin Microbiol. 2012;50(11):3435-42.

50. Liao X, Qiu H, Li R, Guo F, Liu W, Kang M, et al. Risk factors for fluconazole-resistant invasive candidiasis in intensive care unit patients: an analysis from the China Survey of Candidiasis study. J Crit Care. 2015;30(4):862 e1-5.

51. Wang H, Xu YC, Hsueh PR. Epidemiology of candidemia and antifungal susceptibility in invasive Candida species in the Asia-Pacific region. Future Microbiol. 2016;11:1461-77.

52. Verweij PE, Chowdhary A, Melchers WJ, Meis JF. Azole resistance in Aspergillus fumigatus: can we retain the clinical use of mold-active antifungal azoles? Clin Infect Dis. 2016;62(3):362-8.

53. Vallabhaneni S, Cleveland AA, Farley MM, Harrison LH, Schaffner W, Beldavs ZG, et al. Epidemiology and risk factors for echinocandin nonsusceptible Candida glabrata bloodstream infections: data from a large multisite population-based candidemia surveillance program, 2008-2014. Open Forum Infect Dis. 2015;2(4):ofv163.

54. Alexander BD, Johnson MD, Pfeiffer CD, Jimenez-Ortigosa C, Catania J, Booker R, et al. Increasing echinocandin resistance in Candida glabrata: clinical failure correlates with presence of FKS mutations and elevated minimum inhibitory concentrations. Clin Infect Dis. 2013;56(12):1724-32.

55. Beyda ND, John J, Kilic A, Alam MJ, Lasco TM, Garey KW. FKS mutant Candida glabrata: risk factors and outcomes in patients with candidemia. Clin Infect Dis. 2014;59(6):819-25.

56. Biswas C, Chen SC, Halliday C, Martinez E, Rockett RJ, Wang Q, et al. Whole genome sequencing of Candida glabrata for detection of markers of antifungal drug resistance. J VisExp JoVE. 2017;130:e56714.

57. Biswas C, Chen SC, Halliday C, Kennedy K, Playford EG, Marriott DJ, et al. Identification of genetic markers of resistance to echinocandins, azoles and 5-fluorocytosine in Candida glabrata by next-generation sequencing: a feasibility study. Clin Microbiol Infect. 2017;23(9):676 e7e10. 
58. Garnaud C, Botterel F, Sertour N, Bougnoux ME, Dannaoui $E$, Larrat $S$, et al. Next-generation sequencing offers new insights into the resistance of Candida spp. to echinocandins and azoles. J Antimicrob Chemother. 2015;70(9):2556-65.

59. Cuthbertson L, Rogers GB, Walker AW, Oliver A, Hoffman LR, Carroll MP, et al. Implications of multiple freezethawing on respiratory samples for culture-independent analyses. J Cyst Fibros. 2015;14(4):464-7.

60. Nilsson RH, Anslan S, Bahram M, Wurzbacher C, Baldrian P, Tedersoo L. Mycobiome diversity: highthroughput sequencing and identification of fungi. Nat Rev Microbiol. 2019;17(2):95-109.

61. Angebault C, Ghozlane A, Volant S, Botterel F, d'Enfert C, Bougnoux ME. Combined bacterial and fungal intestinal microbiota analyses: impact of storage conditions and DNA extraction protocols. PLoS ONE. 2018;13(8):e0201174.

62. Huseyin CE, Rubio RC, O'Sullivan O, Cotter PD, Scanlan PD. The fungal frontier: a comparative analysis of methods used in the study of the human gut mycobiome. Front Microbiol. 2017;8:1432.

63. Nash AK, Auchtung TA, Wong MC, Smith DP, Gesell JR, Ross MC, et al. The gut mycobiome of the Human Microbiome Project healthy cohort. Microbiome. 2017;5(1):153.

64. van Burik JA, Schreckhise RW, White TC, Bowden RA, Myerson D. Comparison of six extraction techniques for isolation of DNA from filamentous fungi. Med Mycol. 1998;36(5):299-303.

65. Henderson G, Cox F, Kittelmann S, Miri VH, Zethof M, Noel SJ, et al. Effect of DNA extraction methods and sampling techniques on the apparent structure of cow and sheep rumen microbial communities. PLoS ONE. 2013;8(9): e74787.

66. Gow NA, Latge J-P, Munro CA. The fungal cell wall: structure, biosynthesis, and function. Microbiology spectrum. 2017.

67. Smits GJ, Kapteyn JC, van den Ende H, Klis FM. Cell wall dynamics in yeast. Curr Opin Microbiol. 1999;2(4):348-352.

68. Muñoz-Cadavid C, Rudd S, Zaki S, Patel M, Moser S, Brandt $\mathrm{M}$, et al. Improving molecular detection of fungal DNA in formalin-fixed paraffin-embedded tissues: comparison of five tissue DNA extraction methods using panfungal PCR. J Clin Microbiol. 2010;48(6):2147-53.

69. Goldschmidt P, Degorge S, Merabet L, Chaumeil C. Enzymatic treatment of specimens before DNA extraction directly influences molecular detection of infectious agents. PLoS ONE. 2014;9(6):e94886.

70. Vesty A, Biswas K, Taylor MW, Gear K, Douglas RG. Evaluating the impact of DNA extraction method on the representation of human oral bacterial and fungal communities. PLoS ONE. 2017;12(1):e0169877.

71. Rosenbaum J, Usyk M, Chen Z, Zolnik CP, Jones HE, Waldron L, et al. Evaluation of oral cavity DNA extraction methods on bacterial and fungal microbiota. Sci Rep. 2019;9(1):1531.

72. Fredricks DN, Smith C, Meier A. Comparison of six DNA extraction methods for recovery of fungal DNA as assessed by quantitative PCR. J Clin Microbiol. 2005;43(10):5122-8.

73. Huseyin CE, O'Toole PW, Cotter PD, Scanlan PD. Forgotten fungi-the gut mycobiome in human health and disease. FEMS Microbiol Rev. 2017;41(4):479-511.

74. Bokulich NA, Mills DA. Improved selection of internal transcribed spacer-specific primers enables quantitative, ultra-high-throughput profiling of fungal communities. Appl Environ Microbiol. 2013;79(8):2519-26.

75. Begerow D, Nilsson H, Unterseher M, Maier W. Current state and perspectives of fungal DNA barcoding and rapid identification procedures. Appl Microbiol Biotechnol. 2010;87(1):99-108.

76. Schoch CL, Seifert KA, Huhndorf S, Robert V, Spouge JL, Levesque CA, et al. Nuclear ribosomal internal transcribed spacer (ITS) region as a universal DNA barcode marker for Fungi. Proc Natl Acad Sci USA. 2012;109(16):6241-6.

77. Tedersoo L, Anslan S, Bahram M, Põlme S, Riit T, Liiv I, et al. Shotgun metagenomes and multiple primer pairbarcode combinations of amplicons reveal biases in metabarcoding analyses of fungi. MycoKeys. 2015;10:1-43.

78. De Filippis F, Laiola M, Blaiotta G, Ercolini D. Different amplicon targets for sequencing-based studies of fungal diversity. Appl Environ Microbiol. 2017;83(17):e00905-17.

79. Tang J, Iliev ID, Brown J, Underhill DM, Funari VA. Mycobiome: approaches to analysis of intestinal fungi. J Immunol Methods. 2015;421:112-21.

80. Bellemain E, Carlsen T, Brochmann C, Coissac E, Taberlet P, Kauserud H. ITS as an environmental DNA barcode for fungi: an in silico approach reveals potential PCR biases. BMC Microbiol. 2010;10:189.

81. Op De Beeck M, Lievens B, Busschaert P, Declerck S, Vangronsveld J, Colpaert JV. Comparison and validation of some ITS primer pairs useful for fungal metabarcoding studies. PLoS ONE. 2014;9(6):e97629.

82. Tedersoo L, Lindahl B. Fungal identification biases in microbiome projects. Environ Microbiol Rep. 2016;8(5):774-9.

83. Heisel T, Podgorski H, Staley CM, Knights D, Sadowsky MJ, Gale CA. Complementary amplicon-based genomic approaches for the study of fungal communities in humans. PLoS ONE. 2015;10(2):e0116705.

84. Ihrmark K, Bodeker IT, Cruz-Martinez K, Friberg H, Kubartova A, Schenck J, et al. New primers to amplify the fungal ITS2 region-evaluation by 454-sequencing of artificial and natural communities. FEMS Microbiol Ecol. 2012;82(3):666-77.

85. Bakker MG. A fungal mock community control for amplicon sequencing experiments. Mol Ecol Resour. 2018;18(3):541-56.

86. D’Amore R, Ijaz UZ, Schirmer M, Kenny JG, Gregory R, Darby AC, et al. A comprehensive benchmarking study of protocols and sequencing platforms for 16S rRNA community profiling. BMC Genom. 2016;17(1):55.

87. Salter SJ, Cox MJ, Turek EM, Calus ST, Cookson WO, Moffatt MF, et al. Reagent and laboratory contamination can critically impact sequence-based microbiome analyses. BMC Biol. 2014;12:87. 
88. Nguyen NH, Song Z, Bates ST, Branco S, Tedersoo L, Menke J, et al. FUNGuild: an open annotation tool for parsing fungal community datasets by ecological guild. Fungal Ecol. 2016;20:241-8.

89. Quince C, Walker AW, Simpson JT, Loman NJ, Segata N. Shotgun metagenomics, from sampling to analysis. Nat Biotechnol. 2017;35(9):833-44.

90. Marotz CA, Sanders JG, Zuniga C, Zaramela LS, Knight $\mathrm{R}$, Zengler K. Improving saliva shotgun metagenomics by chemical host DNA depletion. Microbiome. 2018;6(1):42.

91. Soergel DA, Dey N, Knight R, Brenner SE. Selection of primers for optimal taxonomic classification of environmental 16S rRNA gene sequences. ISME J. 2012;6(7):1440-4.

92. Mac Aogain M, Chaturvedi V, Chotirmall SH. MycopathologiaGENOMES: the New 'Home' for the Publication of Fungal Genomes. Mycopathologia. 2019;184(5):551-4.

93. Vu D, Groenewald M, de Vries M, Gehrmann T, Stielow $\mathrm{B}$, Eberhardt U, et al. Large-scale generation and analysis of filamentous fungal DNA barcodes boosts coverage for kingdom fungi and reveals thresholds for fungal species and higher taxon delimitation. Stud Mycol. 2019;92:135-54.

94. Donovan PD, Gonzalez G, Higgins DG, Butler G, Ito K. Identification of fungi in shotgun metagenomics datasets. PLoS ONE. 2018;13(2):e0192898.

95. Botterel F, Angebault C, Cabaret O, Stressmann FA, Costa JM, Wallet F, et al. Fungal and Bacterial Diversity of Airway Microbiota in Adults with Cystic Fibrosis: concordance Between Conventional Methods and Ultra-Deep Sequencing, and Their Practical use in the Clinical Laboratory. Mycopathologia. 2018;183(1):171-83.

96. Cote RJ. Aseptic technique for cell culture. Curr Protoc Cell Biol. 2001; Chapter 1:Unit 1:3.

97. Day S, Lalitha P, Haug S, Fothergill AW, Cevallos V, Vijayakumar R, et al. Activity of antibiotics against Fusarium and Aspergillus. $\mathrm{Br} \mathrm{J}$ Ophthalmol. 2009;93(1):116-9.

98. Kerr JR. Bacterial inhibition of fungal growth and pathogenicity. Microbial Ecol Health Dis. 1999;11(3):129-42.

99. Shi X-X, Qiu H-P, Wang J-y, Zhang Z, Wang Y-L, Sun G-C. A handy method to remove bacterial contamination from fungal cultures. PLoS ONE. 2019;14(11):e0224635.

100. Coron N, Pihet M, Fréalle E, Lemeille Y, Pinel C, Pelloux $\mathrm{H}$, et al. Toward the standardization of mycological examination of sputum samples in cystic fibrosis: results from a French multicenter prospective study. Mycopathologia. 2018;183(1):101-17.

101. Chen SC-A, Meyer W, Pashley CH. Challenges in laboratory detection of fungal pathogens in the airways of cystic fibrosis patients. Mycopathologia. 2018;183(1):89-100.

102. Gilgado F, Cano J, Gene J, Sutton DA, Guarro J. Molecular and phenotypic data supporting distinct species statuses for Scedosporium apiospermum and Pseudallescheria boydii and the proposed new species Scedosporium dehoogii. J Clin Microbiol. 2008;46(2):766-71.
103. Lawrence DP, Gannibal PB, Peever TL, Pryor BM. The sections of Alternaria: formalizing species-group concepts. Mycologia. 2013;105(3):530-46.

104. Abliz P, Fukushima K, Takizawa K, Nishimura K. Identification of pathogenic dematiaceous fungi and related taxa based on large subunit ribosomal DNA D1/D2 domain sequence analysis. FEMS Immunol Med Microbiol. 2004;40(1):41-9.

105. Perlin DS, Wiederhold NP. Culture-independent molecular methods for detection of antifungal resistance mechanisms and fungal identification. $J$ Infect Dis. 2017;216(suppl_3):S458-65.

106. Human Microbiome Project C. Structure function and diversity of the healthy human microbiome. Nature. 2012;486(7402):207-14.

107. Stewart CJ, Nelson A, Scribbins D, Marrs EC, Lanyon C, Perry JD, et al. Bacterial and fungal viability in the preterm gut: NEC and sepsis. Arch Dis Child Fetal Neonatal Ed. 2013;98(4):F298-303.

108. Ward TL, Dominguez-Bello MG, Heisel T, Al-Ghalith G, Knights D, Gale CA. Development of the human mycobiome over the first month of life and across body sites. mSystems. 2018;3(3):e00140-17.

109. Romani L. Immunity to fungal infections. Nat Rev Immunol. 2011;11(4):275-88.

110. van de Veerdonk FL, Gresnigt MS, Romani L, Netea MG, Latge JP. Aspergillus fumigatus morphology and dynamic host interactions. Nat Rev Microbiol. 2017;15(11):661-74.

111. Harvill ET. Cultivating our "frienemies": viewing immunity as microbiome management. MBio. 2013;4(2):e00027-13.

112. Cho I, Blaser MJ. The human microbiome: at the interface of health and disease. Nat Rev Genet. 2012;13(4):260-70.

113. Peay KG, Kennedy PG, Talbot JM. Dimensions of biodiversity in the Earth mycobiome. Nat Rev Microbiol. 2016;14(7):434-47.

114. Findley K, Oh J, Yang J, Conlan S, Deming C, Meyer JA, et al. Topographic diversity of fungal and bacterial communities in human skin. Nature. 2013;498:367.

115. Limon JJ, Skalski JH, Underhill DM. Commensal fungi in health and disease. Cell Host Microbe. 2017;22(2):156-65.

116. Ghannoum MA, Jurevic RJ, Mukherjee PK, Cui F, Sikaroodi M, Naqvi A, et al. Characterization of the oral fungal microbiome (mycobiome) in healthy individuals. PLoS Pathog. 2010;6(1):e1000713.

117. Mac Aogain M, Chandrasekaran R, Lim AYH, Low TB, Tan GL, Hassan T, et al. Immunological corollary of the pulmonary mycobiome in bronchiectasis: the CAMEB study. Eur Respir J. 2018;52(1):1800766.

118. Budden KF, Shukla SD, Rehman SF, Bowerman KL, Keely S, Hugenholtz P, et al. Functional effects of the microbiota in chronic respiratory disease. Lancet Respir Med. 2019;7:907-920.

119. Kong HH, Morris A. The emerging importance and challenges of the human mycobiome. Virulence. 2017;8(3):310-2.

120. Tipton L, Müller CL, Kurtz ZD, Huang L, Kleerup E, Morris A, et al. Fungi stabilize connectivity in the lung and skin microbial ecosystems. Microbiome. 2018;6(1):12. 
121. Lyon J. The lung microbiome: key to respiratory Ills? JAMA. 2017;317(17):1713-4.

122. Li X, Leonardi I, Semon A, Doron I, Gao IH, Putzel GG, et al. Response to fungal dysbiosis by gut-resident CX3CR1 + mononuclear phagocytes aggravates allergic airway disease. Cell Host Microbe. 2018;24(6):847-56.

123. Skalski JH, Limon JJ, Sharma P, Gargus MD, Nguyen C, Tang J, et al. Expansion of commensal fungus Wallemia mellicola in the gastrointestinal mycobiota enhances the severity of allergic airway disease in mice. PLoS Pathog. 2018;14(9):e1007260-e.

124. Bacher P, Hohnstein T, Beerbaum E, Rocker M, Blango MG, Kaufmann S, et al. Human anti-fungal Th17 immunity and pathology rely on cross-reactivity against Candida albicans. Cell. 2019;176(6):1340-55 e15.

125. Noverr MC, Falkowski NR, McDonald RA, McKenzie AN, Huffnagle GB. Development of allergic airway disease in mice following antibiotic therapy and fungal microbiota increase: role of host genetics, antigen, and interleukin-13. Infect Immun. 2005;73(1):30-8.

126. Krause R, Moissl-Eichinger C, Halwachs B, Gorkiewicz G, Berg G, Valentin T, et al. Mycobiome in the lower respiratory tract-a clinical perspective. Front Microbiol. 2017;7:2169.

127. Nguyen LD, Viscogliosi E, Delhaes L. The lung mycobiome: an emerging field of the human respiratory microbiome. Front Microbiol. 2015;6:89.

128. Tipton L, Ghedin E, Morris A. The lung mycobiome in the next-generation sequencing era. Virulence. 2017;8(3):334-41.

129. Fraczek MG, Chishimba L, Niven RM, Bromley M, Simpson A, Smyth L, et al. Corticosteroid treatment is associated with increased filamentous fungal burden in allergic fungal disease. J Allergy Clin Immunol. 2018;142(2):407-14.

130. van Woerden HC, Gregory C, Brown R, Marchesi JR, Hoogendoorn B, Matthews IP. Differences in fungi present in induced sputum samples from asthma patients and nonatopic controls: a community based case control study. BMC Infect Dis. 2013;13:69.

131. Goldman DL, Chen Z, Shankar V, Tyberg M, Vicencio A, Burk R. Lower airway microbiota and mycobiota in children with severe asthma. J Allergy Clin Immunol. 2018;141(2):808-11 e7.

132. Chandrasekaran R, Mac Aogáin M, Chalmers JD, Elborn SJ, Chotirmall SH. Geographic variation in the aetiology, epidemiology and microbiology of bronchiectasis. BMC Pulm Med. 2018;18(1):83.

133. Mac Aogain M, Tiew PY, Lim AYH, Low TB, Tan GL, Hassan T, et al. Distinct 'immuno-allertypes' of disease and high frequencies of sensitisation in non-cystic-fibrosis bronchiectasis. Am J Respir Crit Care Med. 2018;199:842-53.

134. Máiz L, Nieto R, Cantón R, Gómez G, de la Pedrosa E, Martinez-García MÁ. Fungi in bronchiectasis: a concise review. Int J Mol Sci. 2018;19(1):142.

135. Veerdonk EKFLvd. The potential impact of the pulmonary microbiome on immunopathogenesis of Aspergillus related lung disease. Eur J Immunol. 2014;44(11):3156-65.
136. Lawani MB, Morris A. The respiratory microbiome of HIV-infected individuals. Expert Rev Anti infect Ther. 2016;14(8):719-29.

137. Cui L, Lucht L, Tipton L, Rogers MB, Fitch A, Kessinger $\mathrm{C}$, et al. Topographic diversity of the respiratory tract mycobiome and alteration in HIV and lung disease. Am J Respir Crit Care Med. 2015;191(8):932-42.

138. Lipuma JJ. The changing microbial epidemiology in cystic fibrosis. Clin Microbiol Rev. 2010;23(2):299-323.

139. Delhaes L, Monchy S, Frealle E, Hubans C, Salleron J, Leroy S, et al. The airway microbiota in cystic fibrosis: a complex fungal and bacterial community-implications for therapeutic management. PLoS ONE. 2012;7(4):e36313.

140. Mounier J, Gouello A, Keravec M, Le Gal S, Pacini G, Debaets $\mathrm{S}$, et al. Use of denaturing high-performance liquid chromatography (DHPLC) to characterize the bacterial and fungal airway microbiota of cystic fibrosis patients. J Microbiol. 2014;52(4):307-14.

141. Willger SD, Grim SL, Dolben EL, Shipunova A, Hampton $\mathrm{TH}$, Morrison HG, et al. Characterization and quantification of the fungal microbiome in serial samples from individuals with cystic fibrosis. Microbiome. 2014;2:40.

142. Kim SH, Clark ST, Surendra A, Copeland JK, Wang PW, Ammar R, et al. Global analysis of the fungal microbiome in cystic fibrosis patients reveals loss of function of the transcriptional repressor $\mathrm{Nrg} 1$ as a mechanism of pathogen adaptation. PLoS Pathog. 2015;11(11):e1005308.

143. Kramer R, Sauer-Heilborn A, Welte T, Guzman CA, Abraham WR, Hofle MG. Cohort Study of Airway Mycobiome in Adult Cystic Fibrosis Patients: differences in Community Structure between Fungi and Bacteria Reveal Predominance of Transient Fungal Elements. J Clin Microbiol. 2015;53(9):2900-7.

144. Richardson M, Bowyer P, Sabino R. The human lung and Aspergillus: You are what you breathe in? Med Mycol. 2019;57(2):S145-54.

145. McTaggart LR, Copeland JK, Surendra A, Wang PW, Husain S, Coburn B, et al. Mycobiome sequencing and analysis applied to fungal community profiling of the lower respiratory tract during fungal pathogenesis. Front Microbiol. 2019;10:512.

146. Hoggard M, Vesty A, Wong G, Montgomery JM, Fourie C, Douglas RG, et al. Characterizing the human mycobiota: a comparison of small subunit rRNA, ITS1, ITS2, and large subunit rRNA genomic targets. Front Microbiol. 2018;9:2208.

147. Li Q, Wang C, Tang C, He Q, Li N, Li J. Dysbiosis of gut fungal microbiota is associated with mucosal inflammation in Crohn's disease. J Clin Gastroenterol. 2014;48(6):513.

148. Ott SJ, Kühbacher T, Musfeldt M, Rosenstiel P, Hellmig S, Rehman A, et al. Fungi and inflammatory bowel diseases: alterations of composition and diversity. Scand J Gastroenterol. 2008;43(7):831-41.

149. Sokol H, Leducq V, Aschard H, Pham H-P, Jegou S, Landman C, et al. Fungal microbiota dysbiosis in IBD. Gut. 2017;66(6):1039-48.

150. Hoarau G, Mukherjee PK, Gower-Rousseau C, Hager C, Chandra J, Retuerto MA, et al. Bacteriome and mycobiome interactions underscore microbial dysbiosis in familial Crohn's disease. MBio. 2016;7(5):e01250-16. 
151. Liguori G, Lamas B, Richard ML, Brandi G, Da Costa G, Hoffmann TW, et al. Fungal dysbiosis in mucosa-associated microbiota of Crohn's disease patients. J Crohn's Colitis. 2015;10(3):296-305.

152. Limon JJ, Tang J, Li D, Wolf AJ, Michelsen KS, Funari V, et al. Malassezia is associated with Crohn's disease and exacerbates colitis in mouse models. Cell Host Microbe. 2019;25(3):377-88 e6.

153. Wheeler ML, Limon JJ, Bar AS, Leal CA, Gargus M, Tang $\mathrm{J}$, et al. Immunological consequences of intestinal fungal dysbiosis. Cell Host Microbe. 2016;19(6):865-73.

154. Sovran B, Planchais J, Jegou S, Straube M, Lamas B, Natividad JM, et al. Enterobacteriaceae are essential for the modulation of colitis severity by fungi. Microbiome. 2018;6(1):152.

155. Mukhopadhya I, Hansen R, Meharg C, Thomson J, Russell $\mathrm{R}$, Berry $\mathrm{S}$, et al. The fungal microbiota of de-novo paediatric inflammatory bowel disease. Microbes Infect. 2015;17(4):304-10.

156. Chehoud C, Albenberg LG, Judge C, Hoffmann C, Grunberg $\mathrm{S}$, Bittinger $\mathrm{K}$, et al. Fungal signature in the gut microbiota of pediatric patients with inflammatory bowel disease. Inflamm Bowel Dis. 2015;21(8):1948-56.

157. Gu Y, Zhou G, Qin X, Huang S, Wang B, Cao H. The potential role of gut mycobiome in irritable bowel syndrome. Front Microbiol. 2019;10:1894.

158. Botschuijver S, Roeselers G, Levin E, Jonkers DM, Welting O, Heinsbroek SEM, et al. Intestinal fungal dysbiosis is associated with visceral hypersensitivity in patients with irritable bowel syndrome and rats. Gastroenterology. 2017;153(4):1026-39.

159. Botschuijver S, Welting O, Levin E, Maria-Ferreira D, Koch E, Montijn RC, et al. Reversal of visceral hypersensitivity in rat by Menthacarin ${ }^{\circledR}$, a proprietary combination of essential oils from peppermint and caraway, coincides with mycobiome modulation. Neurogastroenterol Motil. 2018;30(6):e13299.

160. Aykut B, Pushalkar S, Chen R, Li Q, Abengozar R, Kim JI, et al. The fungal mycobiome promotes pancreatic oncogenesis via activation of MBL. Nature. 2019;574:264-7.

161. Coker OO, Nakatsu G, Dai RZ, Wu WKK, Wong SH, Ng $\mathrm{SC}$, et al. Enteric fungal microbiota dysbiosis and ecological alterations in colorectal cancer. Gut. 2019;68(4):654-62.

162. Luan C, Xie L, Yang X, Miao H, Lv N, Zhang R, et al. Dysbiosis of fungal microbiota in the intestinal mucosa of patients with colorectal adenomas. Sci Rep. 2015;5:7980.

163. Severance EG, Alaedini A, Yang S, Halling M, Gressitt KL, Stallings CR, et al. Gastrointestinal inflammation and associated immune activation in schizophrenia. Schizophr Res. 2012;138(1):48-53.

164. Severance EG, Gressitt KL, Stallings CR, Katsafanas E, Schweinfurth LA, Savage CL, et al. Candida albicans exposures, sex specificity and cognitive deficits in schizophrenia and bipolar disorder. NPJ Schizophr. 2016;2:16018.

165. Strati F, Cavalieri D, Albanese D, De Felice C, Donati C, Hayek J, et al. Altered gut microbiota in Rett syndrome. Microbiome. 2016;4(1):41.
166. Strati F, Cavalieri D, Albanese D, De Felice C, Donati C, Hayek J, et al. New evidences on the altered gut microbiota in autism spectrum disorders. Microbiome. 2017;5(1):24.

167. Dinan TG, Cryan JF. The microbiome-gut-brain axis in health and disease. Gastroenterol Clin N Am. 2017;46(1):77-89.

168. Thijssen AY, Jonkers DM, Leue C, van der Veek PP, Vidakovic-Vukic M, van Rood YR, et al. Dysfunctional cognitions, anxiety and depression in irritable bowel syndrome. J Clin Gastroenterol. 2010;44(10):e236-41.

169. Park CO, Fu X, Jiang X, Pan Y, Teague JE, Collins N, et al. Staged development of long-lived T-cell receptor alphabeta TH17 resident memory T-cell population to Candida albicans after skin infection. J Allergy Clin Immunol. 2018;142(2):647-62.

170. Lagunes L, Rello J. Invasive candidiasis: from mycobiome to infection, therapy, and prevention. Eur J Clin Microbiol Infect Dis. 2016;35(8):1221-6.

171. Jo J-H, Deming C, Kennedy EA, Conlan S, Polley EC, Ng W-I, et al. Diverse human skin fungal communities in children converge in adulthood. J Invest Dermatol. 2016;136(12):2356-63.

172. Kalan L, Loesche M, Hodkinson BP, Heilmann K, Ruthel G, Gardner SE, et al. Redefining the chronic-wound microbiome: fungal communities are prevalent, dynamic, and associated with delayed healing. mBio. 2016;7(5):e01058-16.

173. Wheeler ML, Limon JJ, Underhill DM. Immunity to commensal fungi: detente and disease. Ann Rev Pathol. 2017;12:359-85.

174. Yan D, Issa N, Afifi L, Jeon C, Chang HW, Liao W. The role of the skin and gut microbiome in psoriatic disease. Curr Dermatol Rep. 2017;6(2):94-103.

175. Arron ST, Dimon MT, Li Z, Johnson ME, Wood TA, Feeney L, et al. High Rhodotorula sequences in skin transcriptome of patients with diffuse systemic sclerosis. J Invest Dermatol. 2014;134(8):2138-45.

176. Jo J-H, Kennedy EA, Kong HH. Topographical and physiological differences of the skin mycobiome in health and disease. Virulence. 2016;8(3):324-33.

177. Park HK, Ha M-H, Park S-G, Kim MN, Kim BJ, Kim W. Characterization of the fungal microbiota (mycobiome) in healthy and dandruff-afflicted human scalps. PLoS ONE. 2012;7(2):e32847-e.

178. Johansson HJ, Vallhov H, Holm T, Gehrmann U, Andersson A, Johansson C, et al. Extracellular nanovesicles released from the commensal yeast Malassezia sympodialis are enriched in allergens and interact with cells in human skin. Sci Rep. 2018;8(1):9182.

179. Han SH, Cheon HI, Hur MS, Kim MJ, Jung WH, Lee YW, et al. Analysis of the skin mycobiome in adult patients with atopic dermatitis. Exp Dermatol. 2018;27(4):366-73.

180. Rayner S, Bruhn S, Vallhov H, Andersson A, Billmyre RB, Scheynius A. Identification of small RNAs in extracellular vesicles from the commensal yeast Malassezia sympodialis. Sci Rep. 2017;7:39742.

181. Sparber F, De Gregorio C, Steckholzer S, Ferreira FM, Dolowschiak T, Ruchti F, et al. The skin commensal yeast malassezia triggers a type 17 response that coordinates anti-fungal immunity and exacerbates skin inflammation. Cell Host Microbe. 2019;25(3):389-403. 
182. Kraková L, Šoltys K, Puškárová A, Bučková M, Jeszeová L, Kucharík M, et al. The microbiomes of a XVIII century mummy from the castle of Krásna Hôrka (Slovakia) and its surrounding environment. Environ Microbiol. 2018;20(9):3294-308.

183. Leung MHY, Chan KCK, Lee PKH. Skin fungal community and its correlation with bacterial community of urban Chinese individuals. Microbiome. 2016;4(1):46.

184. Chandra J, Retuerto M, Seite S, Martin R, Kus M, Ghannoum MA, et al. Effect of an emollient on the mycobiome of atopic dermatitis patients. J Drugs Dermatol JDD. 2018;17(10):1039-48.

185. Forbes JD, Bernstein CN, Tremlett H, Van Domselaar G, Knox NC. A fungal world: could the gut mycobiome be involved in neurological disease? Front Microbiol. 2018;9:3249.

186. Tremlett H, Bauer KC, Appel-Cresswell S, Finlay BB, Waubant E. The gut microbiome in human neurological disease: a review. Ann Neurol. 2017;81(3):369-82.

187. Alonso R, Fernandez-Fernandez AM, Pisa D, Carrasco L. Multiple sclerosis and mixed microbial infections. Direct identification of fungi and bacteria in nervous tissue. Neurobiol Dis. 2018;117:42-61.

188. Jangi S, Gandhi R, Cox LM, Li N, von Glehn F, Yan R, et al. Alterations of the human gut microbiome in multiple sclerosis. Nat Commun. 2016;7:12015.

189. Tremlett H, Fadrosh DW, Faruqi AA, Hart J, Roalstad S, Graves J, et al. Gut microbiota composition and relapse risk in pediatric MS: a pilot study. J Neurol Sci. 2016;363:153-7.

190. Tremlett H, Fadrosh DW, Faruqi AA, Zhu F, Hart J, Roalstad S, et al. Gut microbiota in early pediatric multiple sclerosis: a case-control study. Eur J Neurol. 2016;23(8):1308-21.

191. Perlejewski K, Bukowska-Osko I, Nakamura S, Motooka D, Stokowy T, Ploski R, et al. Metagenomic analysis of cerebrospinal fluid from patients with multiple sclerosis. Adv Exp Med Biol. 2016;935:89-98.

192. Jovel J, O'Keefe S, Patterson J, Bording-Jorgensen M, Wang W, Mason AL, et al. Cerebrospinal fluid in a small cohort of patients with multiple sclerosis was generally free of microbial DNA. Front Cell Infect Microbiol. 2016;6:198.

193. Pisa D, Alonso R, Rabano A, Rodal I, Carrasco L. Different brain regions are infected with fungi in Alzheimer's disease. Sci Rep. 2015;5:15015.

194. Alonso R, Pisa D, Fernandez-Fernandez AM, Carrasco L. Infection of fungi and bacteria in brain tissue from elderly persons and patients with Alzheimer's disease. Front Aging Neurosci. 2018;10:159.

195. Alonso R, Pisa D, Fernandez-Fernandez AM, Rabano A, Carrasco L. Fungal infection in neural tissue of patients with amyotrophic lateral sclerosis. Neurobiol Dis. 2017;108:249-60.

196. Laurence M, Benito-Leon J, Calon F. Malassezia and Parkinson's disease. Front Neurol. 2019;10:758.

197. Baxi SN, Portnoy JM, Larenas-Linnemann D, Phipatanakul W. Exposure and health effects of fungi on humans. J Allergy Clin Immunol Pract. 2016;4(3):396-404.

198. Seo S, Ji YG, Yoo Y, Kwon MH, Choung JT. Submicron fungal fragments as another indoor biocontaminant in elementary schools. Environ Sci Process Impacts. 2015;17(6):1164-72.

199. Adams RI, Miletto M, Taylor JW, Bruns TD. Dispersal in microbes: fungi in indoor air are dominated by outdoor air and show dispersal limitation at short distances. ISME J. 2013;7(7):1262-73.

200. Gusareva ES, Acerbi E, Lau KJX, Luhung I, Premkrishnan BNV, Kolundzija S, et al. Microbial communities in the tropical air ecosystem follow a precise diel cycle. Proc Natl Acad Sci USA. 2019;116(46):23299-308.

201. Prussin AJ 2nd, Marr LC. Sources of airborne microorganisms in the built environment. Microbiome. 2015;3:78.

202. Acerbi E, Chenard C, Miller D, Gaultier NE, Heinle CE, Chang VW, et al. Ecological succession of the microbial communities of an air-conditioning cooling coil in the tropics. Indoor Air. 2017;27(2):345-53.

203. Abarenkov K, Adams RI, Laszlo I, Agan A, Ambrosio E, Antonelli A, et al. Annotating public fungal ITS sequences from the built environment according to the MIxS-Built Environment standard-a report from a May 23-24, 2016 workshop (Gothenburg, Sweden). MycoKeys. 2016;16:1-15.

204. Hänninen OO. WHO guidelines for indoor air quality: dampness and mold. In: Adan OCG, Samson RA, editors. Fundamentals of mold growth in indoor environments and strategies for healthy living. Wageningen: Wageningen Academic Publishers; 2011. p. 277-302.

205. Nilsson RH, Taylor AFS, Adams RI, Baschien C, Bengtsson-Palme J, Cangren $\mathrm{P}$, et al. Taxonomic annotation of public fungal ITS sequences from the built environment - a report from an April 10-11, 2017 workshop (Aberdeen, UK). MycoKeys. 2018;28:65-82.

206. Amend AS, Seifert KA, Samson R, Bruns TD. Indoor fungal composition is geographically patterned and more diverse in temperate zones than in the tropics. Proc Natl Acad Sci. 2010;107(31):13748-53.

207. Nonnenmann MW, Coronado G, Thompson B, Griffith WC, Hanson JD, Vesper S, et al. Utilizing pyrosequencing and quantitative PCR to characterize fungal populations among house dust samples. J Environ Monit JEM. 2012;14(8):2038-43.

208. Knutsen AP, Bush RK, Demain JG, Denning DW, Dixit A, Fairs A, et al. Fungi and allergic lower respiratory tract diseases. J Allergy Clin Immunol. 2012;129(2):280-91 quiz 92-3.

209. Cooley JD, Wong WC, Jumper CA, Straus DC. Correlation between the prevalence of certain fungi and sick building syndrome. Occup Environ Med. 1998;55(9):579-84.

210. Straus DC, Cooley JD, Wong WC, Jumper CA. Studies on the role of fungi in Sick Building Syndrome. Arch Environ Health. 2003;58(8):475-8.

211. Bholah R, Subratty AH. Indoor biological contaminants and symptoms of sick building syndrome in office buildings in Mauritius. Int $\mathrm{J}$ Environ Health Res. 2002;12(1):93-8.

212. Tong X, Leung MHY, Wilkins D, Lee PKH. City-scale distribution and dispersal routes of mycobiome in residences. Microbiome. 2017;5(1):131. 
213. Adams RI, Miletto M, Taylor JW, Bruns TD. The diversity and distribution of fungi on residential surfaces. PLoS ONE. 2013;8(11):e78866.

214. Banach M, Szczygłowska R, Pulit J, Bryk M. Building materials with antifungal efficacy enriched with silver nanoparticles. Chem Sci J. 2014;5:085.

215. Vucetic SB, Rudic O, Markov SL, Bera OJ, Vidakovic AM, Skapin AS, et al. Antifungal efficiency assessment of the $\mathrm{TiO} 2$ coating on facade paints. Environ Sci Pollut Res Int. 2014;21(19):11228-37.

216. Adams RI, Bhangar S, Dannemiller KC, Eisen JA, Fierer $\mathrm{N}$, Gilbert JA, et al. Ten questions concerning the microbiomes of buildings. Build Environ. 2016;109:224-34.

217. van der Velden WJ, Netea MG, de Haan AF, Huls GA, Donnelly JP, Blijlevens NM. Role of the mycobiome in human acute graft-versus-host disease. Biol Blood Marrow Transpl. 2013;19(2):329-32.

218. Iliev ID, Funari VA, Taylor KD, Nguyen Q, Reyes CN, Strom SP, et al. Interactions between commensal fungi and the C-type lectin receptor Dectin-1 influence colitis. Science (New York, NY). 2012;336(6086):1314-7.

219. Lai GC, Tan TG, Pavelka N. The mammalian mycobiome: a complex system in a dynamic relationship with the host. Wiley Interdiscip Rev Syst Biol Med. 2019;11(1):e1438.

220. van Nimwegen FA, Penders J, Stobberingh EE, Postma DS, Koppelman GH, Kerkhof M, et al. Mode and place of delivery, gastrointestinal microbiota, and their influence on asthma and atopy. J Allergy Clin Immunol. 2011;128(5):948-55 e1-3.

221. Bjorksten B, Sepp E, Julge K, Voor T, Mikelsaar M. Allergy development and the intestinal microflora during the first year of life. J Allergy Clin Immunol. 2001;108(4):516-20.

222. Frati F, Salvatori C, Incorvaia C, Bellucci A, Di Cara G, Marcucci F, et al. The role of the microbiome in asthma: the gut(-)lung axis. Int J Mol Sci. 2018;20(1):123.

223. Iovene MR, Bombace F, Maresca R, Sapone A, Iardino P, Picardi A, et al. Intestinal dysbiosis and yeast isolation in stool of subjects with autism spectrum disorders. Mycopathologia. 2017;182(3-4):349-63.

224. Sampson TR, Debelius JW, Thron T, Janssen S, Shastri GG, Ilhan ZE, et al. Gut microbiota regulate motor deficits and neuroinflammation in a model of Parkinson's disease. Cell. 2016;167(6): 1469-80 e12.

225. Queiroz-Telles F, Fahal AH, Falci DR, Caceres DH, Chiller T, Pasqualotto AC. Neglected endemic mycoses. Lancet Infect Dis. 2017;17(11):e367-77.

226. Cornely OA, Arikan-Akdagli S, Dannaoui E, Groll AH, Lagrou K, Chakrabarti A, et al. ESCMID and ECMM joint clinical guidelines for the diagnosis and management of mucormycosis 2013. Clin Microbiol Infect. 2014;20(Suppl 3):5-26.

227. Shikanai-Yasuda MA, Mendes RP, Colombo AL, Queiroz-Telles F, Kono ASG, Paniago AMM, et al. Brazilian guidelines for the clinical management of paracoccidioidomycosis. Rev Soc Bras Med Trop. 2017;50(5):715-40.

228. Brown GD, Denning DW, Gow NA, Levitz SM, Netea MG, White TC. Hidden killers: human fungal infections. Sci Transl Med. 2012;4(165):165rv13.
229. Kousha M, Tadi R, Soubani AO. Pulmonary aspergillosis: a clinical review. Eur Respir Rev. 2011;20(121):156-74.

230. Patterson TF, Thompson GR 3rd, Denning DW, Fishman JA, Hadley S, Herbrecht R, et al. Practice guidelines for the diagnosis and management of aspergillosis: 2016 update by the Infectious Diseases Society of America. Clin Infect Dis. 2016;63(4):e1-60.

231. Perfect JR, Cornely OA, Heep M, Ostrosky-Zeichner L, Mullane KM, Maher R, et al. Isavuconazole treatment for rare fungal diseases and for invasive aspergillosis in patients with renal impairment: challenges and lessons of the VITAL trial. Mycoses. 2018;61(7):420-9.

232. Panackal AA, Williamson PR. Fungal infections of the central nervous system. Continuum (Minneap Minn). 2015;21(6 Neuroinfectious Disease):1662-78.

233. Kazan E, Maertens J, Herbrecht R, Weisser M, Gachot B, Vekhoff A, et al. A retrospective series of gut aspergillosis in haematology patients. Clin Microbiol Infect. 2011;17(4):588-94.

234. van Burik JA, Colven R, Spach DH. Cutaneous aspergillosis. J Clin Microbiol. 1998;36(11):3115-21.

235. Cleveland AA, Farley MM, Harrison LH, Stein B, Hollick $\mathrm{R}$, Lockhart SR, et al. Changes in incidence and antifungal drug resistance in candidemia: results from populationbased laboratory surveillance in Atlanta and Baltimore, 2008-2011. Clin Infect Dis. 2012;55(10):1352-61.

236. Morgan J, Meltzer MI, Plikaytis BD, Sofair AN, HuieWhite S, Wilcox S, et al. Excess mortality, hospital stay, and cost due to candidemia: a case-control study using data from population-based candidemia surveillance. Infect Control Hosp Epidemiol. 2005;26(6):540-7.

237. Colombo AL, de Almeida Junior JN, Slavin MA, Chen SC, Sorrell TC. Candida and invasive mould diseases in nonneutropenic critically ill patients and patients with haematological cancer. Lancet Infect Dis. 2017;17(11):e344-56.

238. Oude Lashof AM, Rothova A, Sobel JD, Ruhnke M, Pappas PG, Viscoli C, et al. Ocular manifestations of candidemia. Clin Infect Dis. 2011;53(3):262-8.

239. Li SS, Mody CH. Cryptococcus. Proc Am Thorac Soc. 2010;7(3):186-96.

240. Perfect JR, Dismukes WE, Dromer F, Goldman DL, Graybill JR, Hamill RJ, et al. Clinical practice guidelines for the management of cryptococcal disease: 2010 update by the infectious diseases society of america. Clin Infect Dis. 2010;50(3):291-322.

241. Roden MM, Zaoutis TE, Buchanan WL, Knudsen TA, Sarkisova TA, Schaufele RL, et al. Epidemiology and outcome of zygomycosis: a review of 929 reported cases. Clin Infect Dis. 2005;41(5):634-53.

242. Pak J, Tucci VT, Vincent AL, Sandin RL, Greene JN. Mucormycosis in immunochallenged patients. J Emerg Trauma Shock. 2008;1(2):106-13.

243. Wang XM, Guo LC, Xue SL, Chen YB. Pulmonary mucormycosis: a case report and review of the literature. Oncol Lett. 2016;11(5):3049-53.

244. Castrejon-Perez AD, Welsh EC, Miranda I, OcampoCandiani J, Welsh O. Cutaneous mucormycosis. An Bras Dermatol. 2017;92(3):304-11.

245. Dioverti MV, Cawcutt KA, Abidi M, Sohail MR, Walker RC, Osmon DR. Gastrointestinal mucormycosis in 
immunocompromised hosts. Mycoses. 2015;58(12): 714-8.

246. Maschmeyer G, Helweg-Larsen J, Pagano L, Robin C, Cordonnier C, Schellongowski P, et al. ECIL guidelines for treatment of Pneumocystis jirovecii pneumonia in nonHIV-infected haematology patients. J Antimicrob Chemother. 2016;71(9):2405-13.

247. Ng VL, Yajko DM, Hadley WK. Extrapulmonary pneumocystosis. Clin Microbiol Rev. 1997;10(3):401-18.

248. Kinchen K, Kinchen TH, Inglesby T Jr. Pneumocystis carinii infection of the small intestine. J Natl Med Assoc. 1998;90(10):625-7.

249. Khuu D, Shafir S, Bristow B, Sorvillo F. Blastomycosis mortality rates, United States, 1990-2010. Emerg Infect Dis. 2014;20(11):1789-94.

250. McBride JA, Gauthier GM, Klein BS. Clinical manifestations and treatment of blastomycosis. Clin Chest Med. 2017;38(3):435-49.

251. Chapman SW, Dismukes WE, Proia LA, Bradsher RW, Pappas PG, Threlkeld MG, et al. Clinical practice guidelines for the management of blastomycosis: 2008 update by the Infectious Diseases Society of America. Clin Infect Dis. 2008;46(12):1801-12.

252. Chu JH, Feudtner C, Heydon K, Walsh TJ, Zaoutis TE. Hospitalizations for endemic mycoses: a population-based national study. Clin Infect Dis. 2006;42(6):822-5.

253. Azar MM, Hage CA. Clinical perspectives in the diagnosis and management of histoplasmosis. Clin Chest Med. 2017;38(3):403-15.

254. Wheat LJ, Azar MM, Bahr NC, Spec A, Relich RF, Hage C. Histoplasmosis. Infect Dis Clin North Am. 2016;30(1):207-27.

255. Wheat LJ, Freifeld AG, Kleiman MB, Baddley JW, McKinsey DS, Loyd JE, et al. Clinical practice guidelines for the management of patients with histoplasmosis: 2007 update by the Infectious Diseases Society of America. Clin Infect Dis. 2007;45(7):807-25.

256. Parish JM, Blair JE. Coccidioidomycosis. Mayo Clin Proc. 2008;83(3):343-8 quiz 8-9.

257. Galgiani JN, Ampel NM, Blair JE, Catanzaro A, Geertsma F, Hoover SE, et al. 2016 Infectious Diseases Society of America (IDSA) clinical practice guideline for the treatment of coccidioidomycosis. Clin Infect Dis. 2016;63(6):e112-46.

258. Garcia Garcia SC, Salas Alanis JC, Flores MG, Gonzalez Gonzalez SE, Vera Cabrera L, Ocampo Candiani J. Coccidioidomycosis and the skin: a comprehensive review. An Bras Dermatol. 2015;90(5):610-9.

259. Bisla RS, Taber TH Jr. Coccidioidomycosis of bone and joints. Clin Orthop Relat Res. 1976;121:196-204.

260. McConnell MF, Shi A, Lasco TM, Yoon L. Disseminated coccidioidomycosis with multifocal musculoskeletal disease involvement. Radiol Case Rep. 2017;12(1):141-5.

261. Martinez R. New trends in paracoccidioidomycosis epidemiology. J Fungi (Basel). 2017;3(1):1.

262. Queiroz-Telles F, Escuissato DL. Pulmonary paracoccidioidomycosis. Semin Respir Crit Care Med. 2011;32(6):764-74.

263. Denning DW, Chakrabarti A. Pulmonary and sinus fungal diseases in non-immunocompromised patients. Lancet Infect Dis. 2017;17(11):e357-66.

264. Wong SY, Wong KF. Penicillium marneffei infection in AIDS. Patholog Res Int. 2011;2011:764293.

265. Sirisanthana T, Supparatpinyo K, Perriens J, Nelson KE. Amphotericin B and itraconazole for treatment of disseminated Penicillium marneffei infection in human immunodeficiency virus-infected patients. Clin Infect Dis. 1998;26(5):1107-10.

266. Supparatpinyo K, Schlamm HT. Voriconazole as therapy for systemic Penicillium marneffei infections in AIDS patients. Am J Trop Med Hyg. 2007;77(2):350-3.

267. Hung HG, Lok KH. Intestinal Penicillium marneffei: an unusual cause of chronic diarrhea in an AIDS patient. J Digest Dis. 2010;11(3):189-91.

268. Ko CI, Hung CC, Chen MY, Hsueh PR, Hsiao CH, Wong JM. Endoscopic diagnosis of intestinal Penicilliosis Marneffei: report of three cases and review of the literature. Gastrointest Endosc. 1999;50(1):111-4.

Publisher's Note Springer Nature remains neutral with regard to jurisdictional claims in published maps and institutional affiliations. 